Supporting Information

\title{
Building Bridges in a Series of Estrogen Receptor Degraders: An Application of Metathesis in Medicinal Chemistry.
}

James S. Scott," * Jason Breed, "Rodrigo J. Carbajo," Paul R. Davey," Ryan Greenwood," Hoan K. Huynh,* Teresa Klinowska," Christopher J. Morrow," Thomas A. Moss," Radoslaw Polanski, J. Willem M. Nissink," Jeffrey Varnes," Bin Yang."

`Oncology R\&D, AstraZeneca, Cambridge CB4 OWG, United Kingdom.

*Oncology R\&D, AstraZeneca, R\&D Boston, 35 Gatehouse Drive, Waltham, Massachusetts 02451, United States.

•Discovery Sciences, AstraZeneca, Cambridge CB4 OWG, United Kingdom.

Table of Contents:

Synthesis of compounds:

S2

Biological assays, values \& errors:

PAINS screening:

Molecular Formula Strings:

S15 
General Procedures. All solvents and chemicals used were reagent grade. Flash column chromatography was carried out using prepacked silica cartridges (from $4 \mathrm{~g}$ up to $330 \mathrm{~g}$ ) from Redisep, Biotage, or Crawford and eluted using an Isco Companion system. ${ }^{1} \mathrm{H}$ NMR were recorded on a Bruker Avance DPX400 (400 $\mathrm{MHz}$ ) and were determined in $\mathrm{CDCl}_{3}$ or DMSO- $\mathrm{d}_{6} \cdot{ }^{13} \mathrm{C}$ NMR spectra were recorded at 101 or $175 \mathrm{MHz}$. Chemical shifts are reported in ppm relative to tetramethylsilane (TMS) $(0.00 \mathrm{ppm})$ or solvent peaks as the internal reference and coupling constant $(\mathrm{J})$ values are reported in Hertz $(\mathrm{Hz})$. Splitting patterns are indicated as follows: $\mathrm{s}$, singlet; $\mathrm{d}$, doublet; $\mathrm{t}$, triplet; $\mathrm{m}$, multiplet. Merck precoated thin layer chromatography (TLC) plates (silica gel $60 \mathrm{~F}_{254}, 0.25 \mathrm{~mm}$, art. 5715) were used for TLC analysis. The purity of compounds submitted for screening was $>95 \%$ as determined by UV analysis of liquid chromatography-mass spectroscopy (LC-MS) chromatograms at $254 \mathrm{nM}$ and substantiated using the TAC (Total Absorption Chromatogram). Further support for the purity statement was provided using the MS TIC (Total Ion Current) trace in ESI +ve and -ve ion modes, HRMS and NMR analysis. Solutions were dried over anhydrous magnesium sulfate or sodium sulfate, and solvent was removed by rotary evaporation under reduced pressure. The synthesis of selected examples are described below. All experimental activities involving animals were carried out in accordance with AstraZeneca animal welfare protocols which are consistent with The American Chemical Society Publications rules and ethical guidelines.

\section{(E)-methyl 3-(3,5-difluoro-4-((1R,3R)-2-(2-fluoro-2-methylpropyl)-1,3-dimethyl-2,3,4,9-tetrahydro- 1H-pyrido[3,4-b]indol-1-yl)phenyl)acrylate (5)}
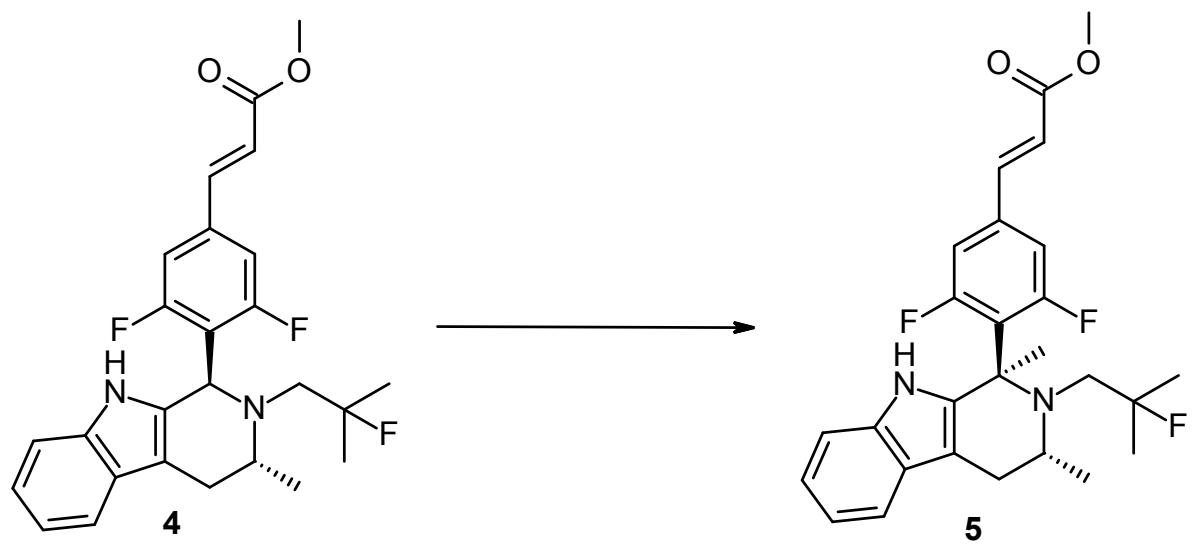

Ceric ammonium nitrate $(0.901 \mathrm{~g}, 1.64 \mathrm{mmol})$ was added in portions to a solution of $(E)$-methyl 3-(3,5difluoro-4-((1R,3R)-2-(2-fluoro-2-methylpropyl)-3-methyl-2,3,4,9-tetrahydro-1H-pyrido[3,4-b]indol-1yl)phenyl)acrylate $2(0.500 \mathrm{~g}, 1.10 \mathrm{mmol})$ in acetonitrile $(8.76 \mathrm{ml}) /$ water $(2.19 \mathrm{ml})$. The reaction was stirred at room temperature for 2 hours and was followed by disappearance of starting material by LCMS. $2 \mathrm{~N} \mathrm{HCl}$ was added $(10 \mathrm{~mL})$ and the reaction was stirred for $5 \mathrm{~min}$, before being extracted with EtOAc $(\mathrm{x} 3)$. The organic phase was washed with brine then dried over $\mathrm{MgSO}_{4}$, filtered and evaporated. The crude product was purified by flash silica chromatography, elution gradient 0 to 20\% MeOH in EtOAc/DCM 1:1. Pure fractions were evaporated to dryness to afford $(R, E)$-1-(2,6-difluoro-4-(3-methoxy-3-oxoprop-1-en-1yl)phenyl)-2-(2-fluoro-2-methylpropyl)-3-methyl-4,9-dihydro-3H-pyrido[3,4-b]indol-2-ium chloride $(0.513 \mathrm{~g}, 95 \%)$ as a red solid. $\mathrm{m} / \mathrm{z}(\mathrm{ES}+), \mathrm{M}+=455$. The nature of the ammonium counterion was not determined emperically, but was assumed to be chloride

Methylmagnesium bromide solution (3M in diethyl ether, $500 \mu 1,1.50 \mathrm{mmol}$ ) was added to a solution of $(R, E)$-1-(2,6-difluoro-4-(3-methoxy-3-oxoprop-1-en-1-yl)phenyl)-2-(2-fluoro-2-methylpropyl)-3-methyl4,9-dihydro-3H-pyrido[3,4-b]indol-2-ium chloride $(369 \mathrm{mg}, 0.75 \mathrm{mmol})$ in $\mathrm{THF}(7.0 \mathrm{~mL})$ at $-10{ }^{\circ} \mathrm{C}$ (iceacetone bath). After stirring for $10 \mathrm{~min}$, an additional portion of methylmagnesium bromide solution ( $3 \mathrm{M}$ in diethyl ether, $500 \mu 1,1.50 \mathrm{mmol}$ ) was added and the reaction was stirred for a further $30 \mathrm{~min}$ at this temperature. The reaction was quenched by addition of saturated $\mathrm{NH}_{4} \mathrm{Cl}$ solution, then the reaction was extracted with EtOAc $(2 \times 20 \mathrm{~mL})$. The combined organics were dried over $\mathrm{Na}_{2} \mathrm{SO}_{4}$, filtered and evaporated. The crude product was purified by flash silica chromatography, elution gradient 0 to $50 \%$ EtOAc in heptane. Pure fractions were evaporated to dryness to afford $(E)$-methyl 3-(3,5-difluoro-4-((1R,3R)-2-(2-fluoro-2- 
methylpropyl)-1,3-dimethyl-2,3,4,9-tetrahydro-1H-pyrido[3,4-b]indol-1-yl)phenyl)acrylate (95 mg, 27\%) 5 was as a beige solid. ${ }^{1} \mathrm{H}$ NMR $\left(500 \mathrm{MHz}, \mathrm{CDCl}_{3}, 27^{\circ} \mathrm{C}\right) 1.04(3 \mathrm{H}, \mathrm{d}), 1.14(3 \mathrm{H}, \mathrm{d}), 1.24(3 \mathrm{H}, \mathrm{d}), 1.90$ $(3 \mathrm{H}, \mathrm{t}), 2.54(1 \mathrm{H}, \mathrm{dd}), 2.67(1 \mathrm{H}, \mathrm{dd}), 2.87-3.06(2 \mathrm{H}, \mathrm{m}), 3.75(1 \mathrm{H}, \mathrm{dt}), 3.78(3 \mathrm{H}, \mathrm{s}), 6.32(1 \mathrm{H}, \mathrm{d}), 6.86$ $(2 \mathrm{H}, \mathrm{d}), 7.07-7.11(1 \mathrm{H}, \mathrm{m}), 7.11-7.15(1 \mathrm{H}, \mathrm{m}), 7.17-7.30(1 \mathrm{H}, \mathrm{m}), 7.44(1 \mathrm{H}, \mathrm{d}), 7.53(1 \mathrm{H}, \mathrm{dd}), 7.74$ $(1 \mathrm{H}, \mathrm{s})$; LRMS for $\mathrm{C}_{27} \mathrm{H}_{29} \mathrm{~F}_{3} \mathrm{~N}_{2} \mathrm{O}_{2}\left(\mathrm{MH}^{+}\right)$; calcd, 471.2254; nominal mass observed, 471.

A by-product was obtained with identical mass as the product, which was identified as the gem-dimethyl alcohol formed from attack of the ester by the Grignard reagent $(87 \mathrm{mg}, 25 \%) .{ }^{1} \mathrm{H}$ NMR $(500 \mathrm{MHz}$, $\left.\mathrm{CDCl}_{3}, 27^{\circ} \mathrm{C}\right) 1.04(3 \mathrm{H}, \mathrm{d}), 1.13(3 \mathrm{H}, \mathrm{d}), 1.17-1.25(3 \mathrm{H}, \mathrm{m}), 1.37(6 \mathrm{H}, \mathrm{d}), 1.87(3 \mathrm{H}, \mathrm{t}), 2.54(1 \mathrm{H}, \mathrm{dd})$, $2.65(1 \mathrm{H}, \mathrm{dd}), 2.91-3.12(2 \mathrm{H}, \mathrm{m}), 3.77(1 \mathrm{H}, \mathrm{dd}), 6.27(1 \mathrm{H}, \mathrm{d}), 6.41(1 \mathrm{H}, \mathrm{d}), 6.73(2 \mathrm{H}, \mathrm{d}), 7.00-7.18$ $(2 \mathrm{H}, \mathrm{m}), 7.16-7.32(1 \mathrm{H}, \mathrm{m}), 7.49-7.58(1 \mathrm{H}, \mathrm{m}), 7.67(1 \mathrm{H}, \mathrm{s})$.

LRMS for $\mathrm{C}_{28} \mathrm{H}_{33} \mathrm{~F}_{3} \mathrm{~N}_{2} \mathrm{O}\left(\mathrm{MH}^{+}\right)$; calcd, 471.2629; nominal mass observed, 471.

Stereochemical assignment was confirmed by the 2D ROESY shows a strong cross peak between methyls $\mathrm{A}$ and $\mathrm{B}$ (dashed lines), confirming that both groups are on the same side of the ring.

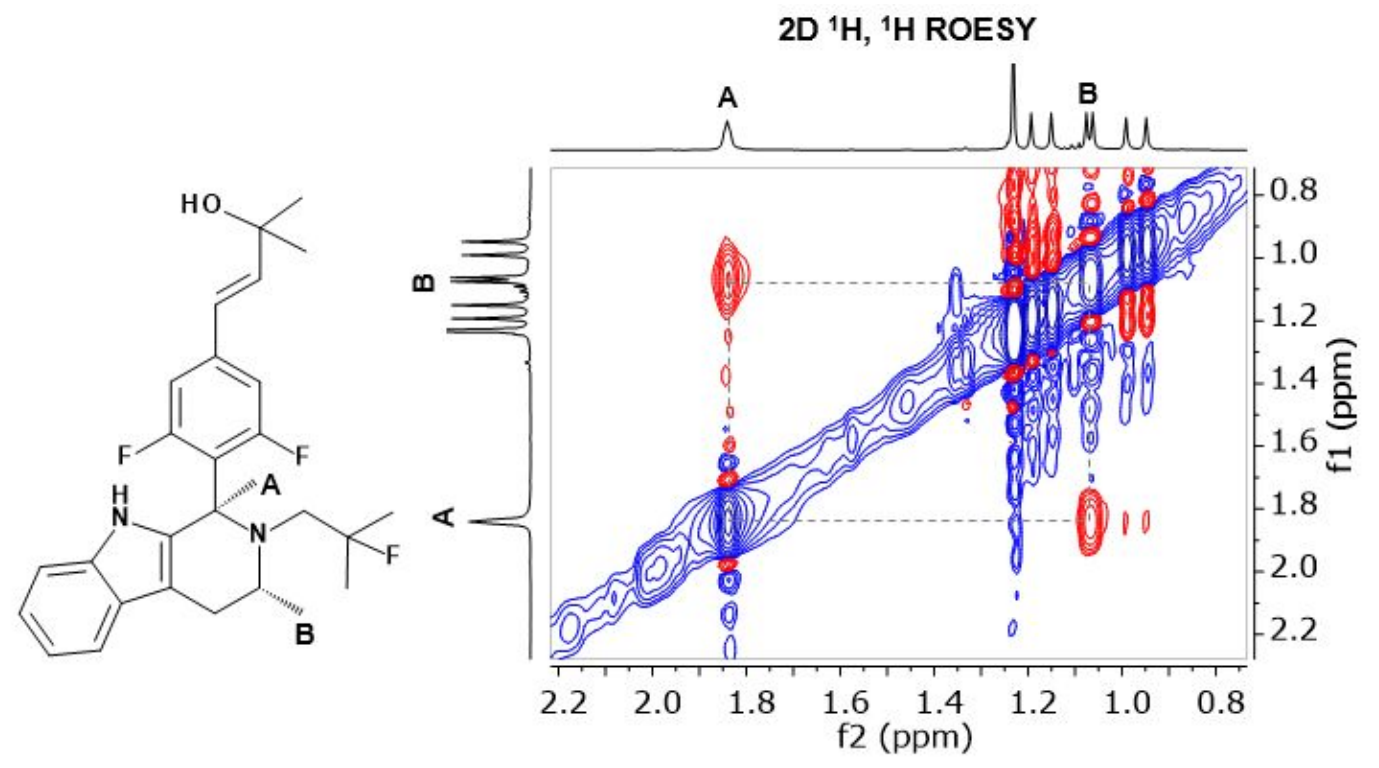

(E)-3-(3,5-difluoro-4-((1R,3R)-2-(2-fluoro-2-methylpropyl)-1,3-dimethyl-2,3,4,9-tetrahydro-1Hpyrido[3,4-b]indol-1-yl)phenyl)acrylic acid (6)
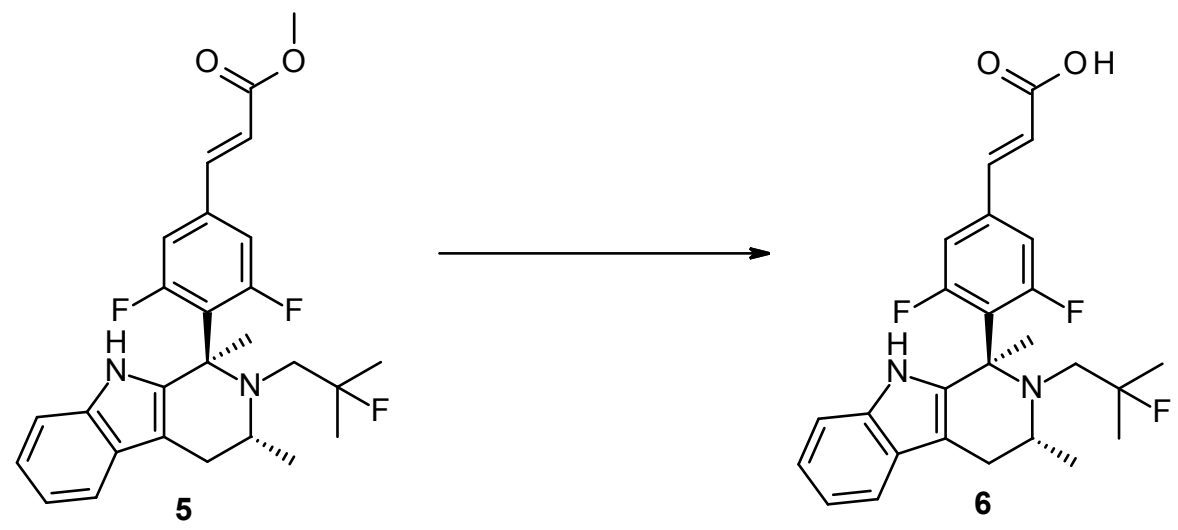

$2 \mathrm{~N} \mathrm{NaOH}$ solution $(0.425 \mathrm{ml}, 0.85 \mathrm{mmol})$ was added to a solution of $(E)$-methyl 3-(3,5-difluoro-4$((1 R, 3 R)$-2-(2-fluoro-2-methylpropyl)-1,3-dimethyl-2,3,4,9-tetrahydro-1H-pyrido[3,4-b]indol-1yl)phenyl)acrylate $3(0.080 \mathrm{~g}, 0.17 \mathrm{mmol})$ in THF $(0.64 \mathrm{ml}) /$ methanol $(0.64 \mathrm{ml})$ and the reaction was stirred at room temperature for 2 hours. The reaction was diluted with EtOAc $(15 \mathrm{~mL})$ and water $(15 \mathrm{~mL})$, then the $\mathrm{pH}$ of the aqueous was adjusted to $\sim 5$ by addition of $2 \mathrm{~N} \mathrm{HCl}$ solution. The layers were separated, then the aqueous layer was extracted with EtOAc $(2 \times 10 \mathrm{~mL})$. The combined organics were dried over $\mathrm{Na}_{2} \mathrm{SO}_{4}$, filtered and evaporated. The crude product was purified by flash silica chromatography, elution 
gradient 0 to $100 \%$ EtOAc in heptane. Pure fractions were evaporated to dryness to afford $(E)-3-(3,5-$ difluoro-4-((1R,3R)-2-(2-fluoro-2-methylpropyl)-1,3-dimethyl-2,3,4,9-tetrahydro-1H-pyrido[3,4-b]indol1-yl)phenyl)acrylic acid $6(0.059 \mathrm{~g}, 75 \%)$ as a beige solid. ${ }^{1} \mathrm{H}$ NMR $\left(500 \mathrm{MHz}, \mathrm{DMSO}-\mathrm{d} 6,27{ }^{\circ} \mathrm{C}\right) 0.97(\mathrm{~d}$, $J=21.5 \mathrm{~Hz}, 3 \mathrm{H}), 1.06(\mathrm{~d}, J=6.6 \mathrm{~Hz}, 3 \mathrm{H}), 1.17(\mathrm{~d}, J=21.5 \mathrm{~Hz}, 3 \mathrm{H}), 1.85(\mathrm{~s}, 3 \mathrm{H}), 2.49(\mathrm{~m}, 1 \mathrm{H}), 2.60(\mathrm{~m}$, $1 \mathrm{H}), 2.86(\mathrm{dd}, J=15.1,5.3 \mathrm{~Hz}, 1 \mathrm{H}), 2.98(\mathrm{t}, J=16.7 \mathrm{~Hz}, 1 \mathrm{H}), 3.63(\mathrm{~m}, 1 \mathrm{H}), 6.59(\mathrm{~d}, J=16.0 \mathrm{~Hz}, 1 \mathrm{H}), 6.94$ $(\mathrm{t}, J=7.4 \mathrm{~Hz}, 1 \mathrm{H}), 6.99(\mathrm{t}, J=7.0 \mathrm{~Hz}, 1 \mathrm{H}), 7.20(\mathrm{~d}, J=8.1 \mathrm{~Hz}, 1 \mathrm{H}), 7.31(\mathrm{~d}, J=12.8 \mathrm{~Hz}, 2 \mathrm{H}), 7.40(\mathrm{~d}, J$ $=7.8 \mathrm{~Hz}, 1 \mathrm{H}), 7.45(\mathrm{~d}, J=15.9 \mathrm{~Hz}, 1 \mathrm{H}), 10.69(\mathrm{~s}, 1 \mathrm{H}), 12.51(\mathrm{~s}, \mathrm{br}, 1 \mathrm{H}) ;{ }^{13} \mathrm{C}$ NMR $(125 \mathrm{MHz}, \mathrm{DMSO}-\mathrm{d} 6$, $\left.27{ }^{\circ} \mathrm{C}\right) 17.0,23.7(\mathrm{~d}, J=24.9 \mathrm{~Hz}), 24.5,25.6(\mathrm{~d}, J=24.9 \mathrm{~Hz}), 26.4,50.6(\mathrm{~d}, J=5.1 \mathrm{~Hz}), 53.4(\mathrm{t}, J=21.0$ $\mathrm{Hz}), 60.3,97.0(\mathrm{~d}, J=167.4 \mathrm{~Hz}), 104.5,110.9,111.9(J=26.9 \mathrm{~Hz}, 2 \mathrm{C}), 117.7,118.1,120.4,122.0,123.6$ $(\mathrm{t}, J=12.1), 126.6,135.6(\mathrm{t}, J=11.9 \mathrm{~Hz}), 136.0,137.7,140.9,161.5(J=250.7 \mathrm{~Hz}, 2 \mathrm{C}), 167.2 ;{ }^{19} \mathrm{~F}$ NMR (376 MHz, DMSO-d6, $27{ }^{\circ} \mathrm{C}$ ) -106.5 (2F), -133.9; HRMS (ESI) for $\mathrm{C}_{26} \mathrm{H}_{27} \mathrm{~F}_{3} \mathrm{~N}_{2} \mathrm{O}_{2}\left(\mathrm{MH}^{+}\right)$; calcd, 457.20974; found, 457.21008 .

\section{(S)-2-((2-fluoro-2-methylpropyl)amino)-3-(1H-indol-3-yl)propan-1-ol}
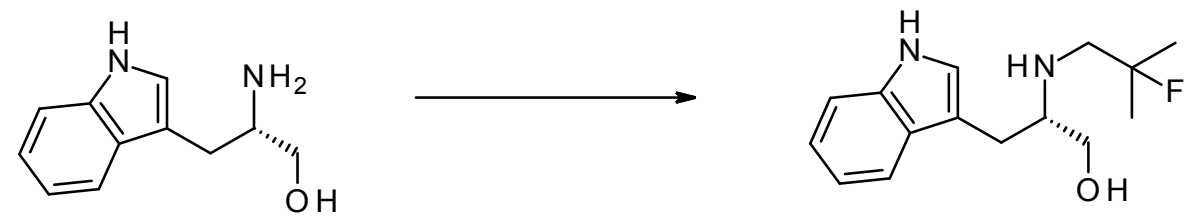

2-Fluoro-2-methylpropyl trifluoromethanesulfonate (7.36 g, $32.8 \mathrm{mmol})$ was added to a solution of $(S)$-2amino-3-(1H-indol-3-yl)propan-1-ol (5.00 g, $26.3 \mathrm{mmol})$ and DIPEA (7.95 ml, $46.0 \mathrm{mmol})$ in 1,4-dioxane $(57.8 \mathrm{ml})$ and the reaction was heated to $85{ }^{\circ} \mathrm{C}$ overnight. The volatiles were evaporated, then the crude product was purified by flash silica chromatography, elution gradient 0 to $100 \%$ EtOAc in heptane. Pure fractions were evaporated to dryness to afford $(S)$-2-((2-fluoro-2-methylpropyl)amino)-3-(1H-indol-3yl)propan-1-ol (6.25 g, 90\%) as a light brown oil. ${ }^{1} \mathrm{H}$ NMR $\left(500 \mathrm{MHz}, \mathrm{CDCl}_{3}, 27{ }^{\circ} \mathrm{C}\right) 1.33(3 \mathrm{H}, \mathrm{d}), 1.37$ $(3 \mathrm{H}, \mathrm{d}), 2.63(1 \mathrm{H}, \mathrm{dd}), 2.82-3.00(3 \mathrm{H}, \mathrm{m}), 2.99-3.11(1 \mathrm{H}, \mathrm{m}), 3.37(1 \mathrm{H}, \mathrm{dd}), 3.65(1 \mathrm{H}, \mathrm{dd}), 7.03(1 \mathrm{H}, \mathrm{d})$,

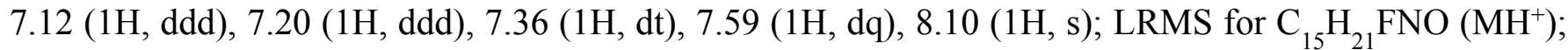
calcd, 265.1638; nominal mass observed, 265.

\section{((1R,3S)-1-(4-bromo-2,6-difluorophenyl)-2-(2-fluoro-2-methylpropyl)-2,3,4,9-tetrahydro-1H-}

\section{pyrido[3,4-b]indol-3-yl)methanol (9)}

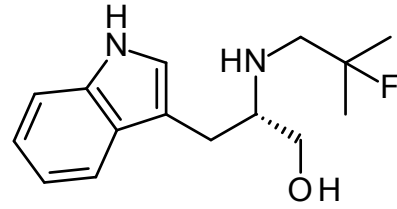

(S)-2-((2-Fluoro-2-methylpropyl)amino)-3-(1H-indol-3-yl)propan-1-ol (2.00 g, $6.81 \mathrm{mmol})$ and 4-bromo2,6-difluorobenzaldehyde $(1.58 \mathrm{~g}, 7.15 \mathrm{mmol})$ were heated in toluene $(30.6 \mathrm{ml}) /$ acetic acid $(3.40 \mathrm{ml})$ to $85^{\circ} \mathrm{C}$ for 4 hours. After cooling, the volatiles were evaporated, then the crude product was purified by ion exchange chromatography, using an SCX-2 column. The desired product was eluted from the column using $1 \mathrm{M} \mathrm{NH} / 3$ MeOH and pure fractions were evaporated to dryness to give a pale yellow foam. The crude product was purified by flash silica chromatography, elution gradient 0 to $50 \%$ EtOAc in heptane. Pure fractions were evaporated to dryness to afford ((1R,3S)-1-(4-bromo-2,6-difluorophenyl)-2-(2-fluoro-2methylpropyl)-2,3,4,9-tetrahydro-1H-pyrido[3,4-b]indol-3-yl)methanol 9 (2.65 g, 83\%) as a pale yellow solid. ${ }^{1} \mathrm{H}$ NMR $\left(500 \mathrm{MHz}, \mathrm{CDCl}_{3}, 27^{\circ} \mathrm{C}\right) 1.31(3 \mathrm{H}, \mathrm{d}), 1.42(3 \mathrm{H}, \mathrm{d}), 2.30(1 \mathrm{H}, \mathrm{d}), 2.59-2.70(2 \mathrm{H}, \mathrm{m}), 2.70$ $2.82(2 \mathrm{H}, \mathrm{m}), 3.50(1 \mathrm{H}, \mathrm{dt}), 3.55-3.70(2 \mathrm{H}, \mathrm{m}), 5.53(1 \mathrm{H}, \mathrm{d}), 7.01-7.08(2 \mathrm{H}, \mathrm{m}), 7.12(1 \mathrm{H}, \mathrm{ddd}), 7.14-7.18$ 
$(1 \mathrm{H}, \mathrm{m}), 7.25-7.31(1 \mathrm{H}, \mathrm{m}), 7.45-7.56(1 \mathrm{H}, \mathrm{m}), 7.72(1 \mathrm{H}, \mathrm{s})$; LRMS for $\mathrm{C}_{22} \mathrm{H}_{22} \mathrm{BrF}_{3} \mathrm{~N}_{2} \mathrm{O}\left(\mathrm{MH}^{+}\right)$; calcd, 467.0940; nominal mass observed, 467.

(1R,3S)-1-(4-bromo-2,6-difluorophenyl)-2-(2-fluoro-2-methylpropyl)-2,3,4,9-tetrahydro-1Hpyrido[3,4-b]indole-3-carbaldehyde (10)<smiles>CC(C)(F)CN1C(c2c(F)cc(Br)cc2F)c2[nH]c3ccccc3c2C[C@@H]1CO</smiles><smiles>CC(C)(F)CN1[C@H](C=O)Cc2c([nH]c3ccccc23)[C@@H]1c1c(F)cc(Br)cc1F</smiles>

$\mathrm{SO}_{3}$-pyridine complex $(2.00 \mathrm{~g}, 12.5 \mathrm{mmol})$ was added to a solution of ((1R,3S)-1-(4-bromo-2,6difluorophenyl)-2-(2-fluoro-2-methylpropyl)-2,3,4,9-tetrahydro-1H-pyrido[3,4-b]indol-3-yl)methanol 9 $(2.60 \mathrm{~g}, 5.56 \mathrm{mmol})$ and triethylamine $(1.94 \mathrm{ml}, 13.9 \mathrm{mmol})$ in DCM (12.94 ml) / DMSO (12.94 ml) at 0 ${ }^{\circ} \mathrm{C}$. The reaction was allowed to warm to room temperature over 4 hours. The reaction was diluted with DCM $(100 \mathrm{~mL})$ and water $(100 \mathrm{~mL})$, then the layers were separated. The organic layer was washed with brine $(100 \mathrm{~mL})$, then dried over $\mathrm{MgSO}_{4}$, filtered and evaporated. The crude product was purified by flash silica chromatography, elution gradient 0 to $50 \%$ EtOAc in heptane. Pure fractions were evaporated to dryness to afford (1R,3S)-1-(4-bromo-2,6-difluorophenyl)-2-(2-fluoro-2-methylpropyl)-2,3,4,9tetrahydro-1H-pyrido[3,4-b]indole-3-carbaldehyde $\mathbf{1 0}(2.260 \mathrm{~g}, 87 \%)$ as a pale yellow solid. ${ }^{1} \mathrm{H}$ NMR $(500$ $\left.\mathrm{MHz}, \mathrm{CDCl}_{3}, 27^{\circ} \mathrm{C}\right) 1.10(3 \mathrm{H}, \mathrm{d}), 1.22(3 \mathrm{H}, \mathrm{d}), 2.59(1 \mathrm{H}, \mathrm{dd}), 3.24-3.27(2 \mathrm{H}, \mathrm{m}), 3.31(1 \mathrm{H}, \mathrm{t}), 4.29-4.37$ $(1 \mathrm{H}, \mathrm{m}), 5.87(1 \mathrm{H}, \mathrm{s}), 7.04-7.08(2 \mathrm{H}, \mathrm{m}), 7.09-7.16(2 \mathrm{H}, \mathrm{m}), 7.19-7.22(1 \mathrm{H}, \mathrm{m}), 7.41(1 \mathrm{H}, \mathrm{s}), 7.49-7.56$ $(1 \mathrm{H}, \mathrm{m}), 9.69(1 \mathrm{H}, \mathrm{s})$; LRMS for $\mathrm{C}_{22} \mathrm{H}_{20} \mathrm{BrF}_{3} \mathrm{~N}_{2} \mathrm{O}\left(\mathrm{MH}^{+}\right)$; calcd, 465.0784; nominal mass observed, 465.

\section{(1R,3S)-1-(4-bromo-2,6-difluorophenyl)-2-(2-fluoro-2-methylpropyl)-3-vinyl-2,3,4,9-tetrahydro-}

\section{H-pyrido[3,4-b]indole (11)}<smiles>CC(C)(F)CN1C(c2c(F)cc(Br)cc2F)c2[nH]c3ccccc3c2C[C@H]1C=O</smiles>
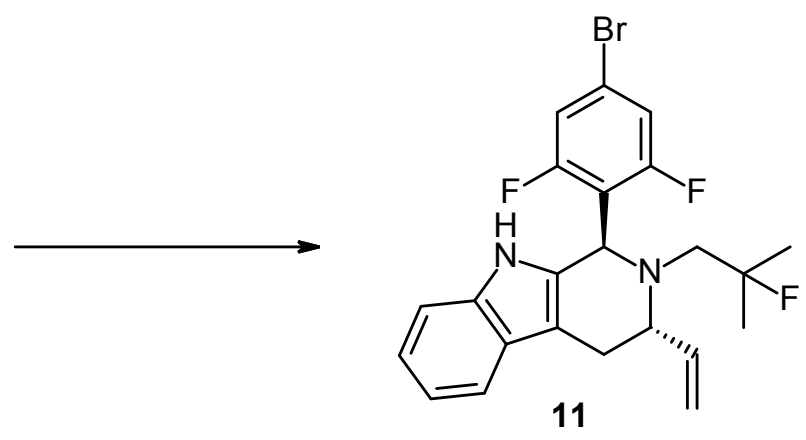

KHMDS solution (1M in THF, $14.44 \mathrm{ml}, 14.44 \mathrm{mmol}$ ) was added to a suspension of methyltriphenylphosphonium bromide $(4.84 \mathrm{~g}, 13.5 \mathrm{mmol})$ in THF $(8.12 \mathrm{ml})$ at $0{ }^{\circ} \mathrm{C}$ and the reaction was stirred for $15 \mathrm{~min}$, before cooling to $-78{ }^{\circ} \mathrm{C}$. (1R,3S)-1-(4-bromo-2,6-difluorophenyl)-2-(2-fluoro-2methylpropyl)-2,3,4,9-tetrahydro-1H-pyrido[3,4-b]indole-3-carbaldehyde $\mathbf{1 0}$ (2.10 g, $4.51 \mathrm{mmol})$ was added in THF $(10 \mathrm{~mL})$ dropwise and the reaction was stirred for $30 \mathrm{~min}$ before being allowed to warm to 0 ${ }^{\circ} \mathrm{C}$ over 1 hour. The reaction was quenched by addition of aqueous $\mathrm{NH}_{4} \mathrm{Cl}$ solution $(50 \mathrm{~mL})$ and extracted with EtOAc $(2 \times 50 \mathrm{~mL})$. The organic was dried over $\mathrm{Na}_{2} \mathrm{SO}_{4}$, filtered and evaporated. The crude product was purified by flash silica chromatography, elution gradient 0 to $50 \%$ EtOAc in heptane. Pure fractions were evaporated to dryness to afford (1R,3S)-1-(4-bromo-2,6-difluorophenyl)-2-(2-fluoro-2methylpropyl)-3-vinyl-2,3,4,9-tetrahydro-1H-pyrido[3,4-b]indole $11(0.845 \mathrm{~g}, 40 \%)$ as a pale yellow solid. 
${ }^{1} \mathrm{H}$ NMR $\left(500 \mathrm{MHz}, \mathrm{CDCl}_{3}, 27^{\circ} \mathrm{C}\right) 1.17(3 \mathrm{H}, \mathrm{d}), 1.22-1.29(3 \mathrm{H}, \mathrm{m}), 2.34(1 \mathrm{H}, \mathrm{dd}), 2.80(1 \mathrm{H}, \mathrm{ddd}), 2.94$ $(1 \mathrm{H}, \mathrm{dd}), 3.20(1 \mathrm{H}, \mathrm{ddd}), 3.98(1 \mathrm{H}, \mathrm{dt}), 5.22-5.30(2 \mathrm{H}, \mathrm{m}), 5.32(1 \mathrm{H}, \mathrm{s}), 5.89(1 \mathrm{H}, \mathrm{dddd}), 7.03-7.07(2 \mathrm{H}$, m), 7.08-7.16 $(2 \mathrm{H}, \mathrm{m}), 7.21-7.24(1 \mathrm{H}, \mathrm{m}), 7.39(1 \mathrm{H}, \mathrm{s}), 7.51-7.60(1 \mathrm{H}, \mathrm{m})$; LRMS for $\mathrm{C}_{23} \mathrm{H}_{22} \mathrm{BrF}_{3} \mathrm{~N}_{2}$ $\left(\mathrm{MH}^{+}\right)$; calcd, 463.0991; nominal mass observed, (M-H) 461.

(1R,3S)-1-allyl-1-(4-bromo-2,6-difluorophenyl)-2-(2-fluoro-2-methylpropyl)-3-vinyl-2,3,4,9tetrahydro-1H-pyrido[3,4-b]indole (12)<smiles>C=C[C@@H]1Cc2c([nH]c3ccccc23)C(c2c(F)cc(Br)cc2F)N1CC(C)(C)F</smiles>
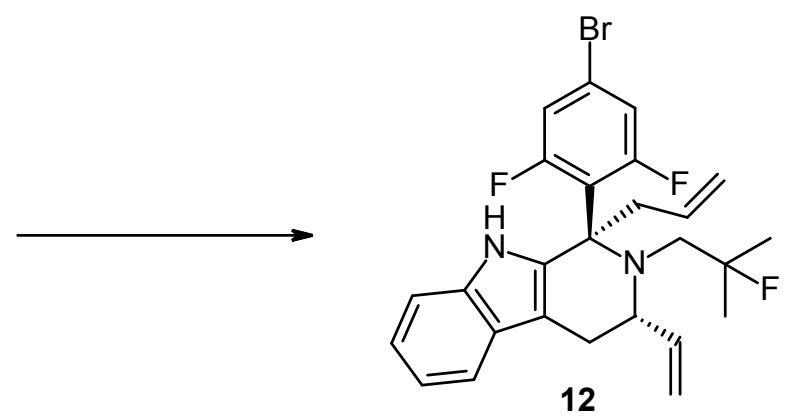

Cerium (IV) ammoniun nitrate $(5.19 \mathrm{~g}, 9.47 \mathrm{mmol})$ was added to a solution of (1R,3S)-1-(4-bromo-2,6difluorophenyl)-2-(2-fluoro-2-methylpropyl)-3-vinyl-2,3,4,9-tetrahydro-1H-pyrido[3,4-b]indole 11 (1.95 $\mathrm{g}, 4.21 \mathrm{mmol})$ in $\mathrm{MeCN}(13.47 \mathrm{ml}) /$ water $(3.37 \mathrm{ml})$ and the reaction was stirred at room temperature for 2 hours. EtOAc $(50 \mathrm{~mL})$ and brine $(50 \mathrm{~mL})$ were added and the biphasic mixture was stirred for $15 \mathrm{~min}$. The layers were separated and the aqueous layer was extracted with EtOAc $(2 \times 25 \mathrm{~mL})$. The combined organics were washed with brine $(50 \mathrm{~mL})$, dried over $\mathrm{MgSO}_{4}$, filtered and evaporated. The crude product was purified by flash silica chromatography, elution gradient 0 to $25 \% \mathrm{MeOH}$ in EtOAc. Pure fractions were evaporated to dryness to afford (S)-1-(4-bromo-2,6-difluorophenyl)-2-(2-fluoro-2-methylpropyl)-3vinyl-4,9-dihydro-3H-pyrido[3,4-b]indol-2-ium as a red solid.

Allylmagnesium bromide (1M in THF, $3.30 \mathrm{~mL}, 3.30 \mathrm{mmol})$ was added to a solution of $(S)$-1-(4-bromo2,6-difluorophenyl)-2-(2-fluoro-2-methylpropyl)-3-vinyl-4,9-dihydro-3H-pyrido[3,4-b]indol-2-ium,

chloride $(548 \mathrm{mg}, 1.10 \mathrm{mmol})$ in THF $(5.50 \mathrm{~mL})$ at $-78{ }^{\circ} \mathrm{C}$ and the reaction was stirred for 1 hour. The reaction was quenched by addition of aqueous $\mathrm{NH}_{4} \mathrm{Cl}$ solution and extracted with EtOAc. The organic phase was dried and evaporated, then the crude product was purified by flash silica chromatography, elution gradient 0 to $25 \%$ EtOAc in heptane. Pure fractions were evaporated to dryness to afford $(1 R, 3 S)-1$-allyl1-(4-bromo-2,6-difluorophenyl)-2-(2-fluoro-2-methylpropyl)-3-vinyl-2,3,4,9-tetrahydro-1H-pyrido[3,4b]indole $12(102 \mathrm{mg}, 18 \%)$ as a pale yellow solid. ${ }^{1} \mathrm{H}$ NMR $\left(500 \mathrm{MHz}, \mathrm{CDCl}_{3}, 27{ }^{\circ} \mathrm{C}\right) 1.00(3 \mathrm{H}, \mathrm{d}), 1.28$ $(3 \mathrm{H}, \mathrm{d}), 2.60-2.85(5 \mathrm{H}, \mathrm{m}), 3.51(1 \mathrm{H}, \mathrm{d}), 3.84(1 \mathrm{H}, \mathrm{q}), 5.04-5.12(2 \mathrm{H}, \mathrm{m}), 5.15(1 \mathrm{H}, \mathrm{dt}), 5.24(1 \mathrm{H}, \mathrm{d}), 5.74$ $(1 \mathrm{H}, \mathrm{dtd}), 5.90-6.02(1 \mathrm{H}, \mathrm{m}), 6.91(2 \mathrm{H}, \mathrm{dd}), 7.03(1 \mathrm{H}, \mathrm{ddd}), 7.09(1 \mathrm{H}, \mathrm{ddd}), 7.20(1 \mathrm{H}, \mathrm{dt}), 7.45-7.50(1 \mathrm{H}$, m), $8.21(1 \mathrm{H}, \mathrm{s})$; LRMS for $\mathrm{C}_{26} \mathrm{H}_{26} \mathrm{BrF}_{3} \mathrm{~N}_{2}\left(\mathrm{MH}^{+}\right)$; calcd, 503.1304; nominal mass observed, 503.

(6R, 10S)-6-(4-bromo-2,6-difluorophenyl)-12-(2-fluoro-2-methylpropyl)-6,7,10,11-tetrahydro-5H-

\section{6,10-epiminocycloocta[b]indole (13)}<smiles>C=CC[C@@]1(c2c(F)cc(Br)cc2F)c2[nH]c3ccccc3c2C[C@H](C=C)N1CC(C)(C)F</smiles>

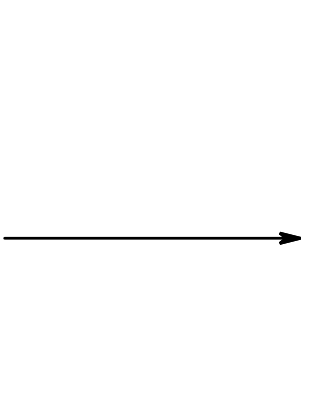<smiles>CCN1[C@@H]2C=C(C(C)(C)F)C[C@]1(c1c(F)cc(Br)cc1F)c1[nH]c3ccccc3c1C2</smiles> 
Grubbs (II) catalyst (10.6 mg, $0.01 \mathrm{mmol})$ was added to a degassed solution of (1R,3S)-1-allyl-1-(4-bromo2,6-difluorophenyl)-2-(2-fluoro-2-methylpropyl)-3-vinyl-2,3,4,9-tetrahydro-1H-pyrido[3,4-b]indole 12 $(126 \mathrm{mg}, 0.25 \mathrm{mmol})$ in toluene $(2.50 \mathrm{~mL})$ and the reaction was stirred at $60{ }^{\circ} \mathrm{C}$ for 2 hours. An additional portion of grubbs (II) catalyst $(10.6 \mathrm{mg}, 0.01 \mathrm{mmol})$ was added and the reaction was stirred for a further 1 hour at $60{ }^{\circ} \mathrm{C}$. The volatiles were evaporated, then the crude product was purified by flash silica chromatography, elution gradient 0 to $25 \%$ EtOAc in heptane. Pure fractions were evaporated to dryness to afford (6R,10S)-6-(4-bromo-2,6-difluorophenyl)-12-(2-fluoro-2-methylpropyl)-6,7,10,11-tetrahydro5H-6,10-epiminocycloocta[b]indole $13(110 \mathrm{mg}, 93 \%)$ as a pale yellow solid. ${ }^{1} \mathrm{H}$ NMR $\left(500 \mathrm{MHz}, \mathrm{CDCl}_{3}\right.$, $\left.27{ }^{\circ} \mathrm{C}\right) 1.10-1.27(6 \mathrm{H}, \mathrm{m}), 2.32(1 \mathrm{H}, \mathrm{dd}), 2.37-2.47(1 \mathrm{H}, \mathrm{m}), 2.67(1 \mathrm{H}, \mathrm{dd}), 2.86(1 \mathrm{H}, \mathrm{t}), 3.18-3.26(1 \mathrm{H}$, m), $3.32(1 \mathrm{H}, \mathrm{d}), 4.03(1 \mathrm{H}, \mathrm{s}), 5.64(1 \mathrm{H}, \mathrm{d}), 5.71-5.79(1 \mathrm{H}, \mathrm{m}), 6.90(1 \mathrm{H}, \mathrm{dt}), 7.04-7.16(3 \mathrm{H}, \mathrm{m}), 7.16-$ $7.20(1 \mathrm{H}, \mathrm{m}), 7.23(1 \mathrm{H}, \mathrm{s}), 7.44-7.52(1 \mathrm{H}, \mathrm{m})$; LRMS for $\mathrm{C}_{24} \mathrm{H}_{22} \mathrm{BrF}_{3} \mathrm{~N}_{2}\left(\mathrm{MH}^{+}\right)$; calcd, 475.0991; nominal mass observed, 475 .

\section{Methyl (E)-3-(3,5-difluoro-4-((6R, 10S)-12-(2-fluoro-2-methylpropyl)-5,7,10,11-tetrahydro-6H- 6,10-epiminocycloocta[b]indol-6-yl)phenyl)acrylate}
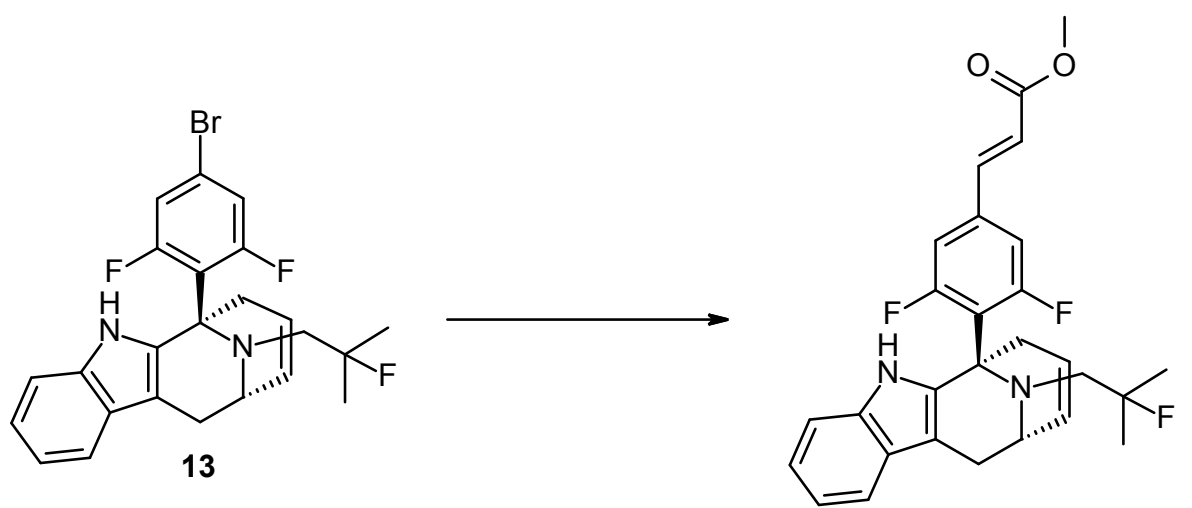

Methyl acrylate $(170 \mu \mathrm{l}, 1.89 \mathrm{mmol})$ was added to a degassed suspension of $(6 R, 10 S)$-6-(4-bromo-2,6difluorophenyl)-12-(2-fluoro-2-methylpropyl)-6,7,10,11-tetrahydro-5H-6,10-epiminocycloocta[b]indole (100 mg, $0.19 \mathrm{mmol})$ 13, DIPEA $(65.4 \mu \mathrm{l}, 0.38 \mathrm{mmol})$ and Pd-118 $(6.13 \mathrm{mg}, 9.47 \mu \mathrm{mol})$ in 1,4-dioxane $(1.25 \mathrm{~mL})$ in a microwave vial. The reaction was heated to $140{ }^{\circ} \mathrm{C}$ for 2 hours. The volatiles were evaporated, then the crude product was purified by flash silica chromatography, elution gradient 0 to $50 \%$ EtOAc in heptane. Pure fractions were evaporated to dryness to afford methyl (E)-3-(3,5-difluoro-4((6R,10S)-12-(2-fluoro-2-methylpropyl)-5,7,10,11-tetrahydro-6H-6,10-epiminocycloocta[b]indol-6yl)phenyl)acrylate $(58.0 \mathrm{mg}, 64 \%)$ as a pale yellow solid. ${ }^{1} \mathrm{H} \mathrm{NMR}\left(500 \mathrm{MHz}, \mathrm{CDCl}_{3}, 27{ }^{\circ} \mathrm{C}\right) 1.17(6 \mathrm{H}$, dd), $2.33(1 \mathrm{H}, \mathrm{dd}), 2.40-2.50(1 \mathrm{H}, \mathrm{m}), 2.68(1 \mathrm{H}, \mathrm{dd}), 2.87(1 \mathrm{H}, \mathrm{t}), 3.23(1 \mathrm{H}, \mathrm{dd}), 3.36(1 \mathrm{H}, \mathrm{d}), 3.80(3 \mathrm{H}$, s), $4.04(1 \mathrm{H}, \mathrm{s}), 5.65(1 \mathrm{H}, \mathrm{d}), 5.75(1 \mathrm{H}, \mathrm{d}), 6.37(1 \mathrm{H}, \mathrm{d}), 6.83(1 \mathrm{H}, \mathrm{d}), 7.03(1 \mathrm{H}, \mathrm{dd}), 7.05-7.11(2 \mathrm{H}, \mathrm{m})$, 7.15-7.20 $(1 \mathrm{H}, \mathrm{m}), 7.41(1 \mathrm{H}, \mathrm{s}), 7.47(1 \mathrm{H}, \mathrm{d}), 7.49(1 \mathrm{H}, \mathrm{t})$; LRMS for $\mathrm{C}_{28} \mathrm{H}_{27} \mathrm{~F}_{3} \mathrm{~N}_{2} \mathrm{O}_{2}\left(\mathrm{MH}^{+}\right)$; calcd, 481.2025; nominal mass observed, 481.

(E)-3-(3,5-difluoro-4-((6R, 10S)-12-(2-fluoro-2-methylpropyl)-5,7,10,11-tetrahydro-6H-6,10epiminocycloocta[b]indol-6-yl)phenyl)acrylic acid (7) 


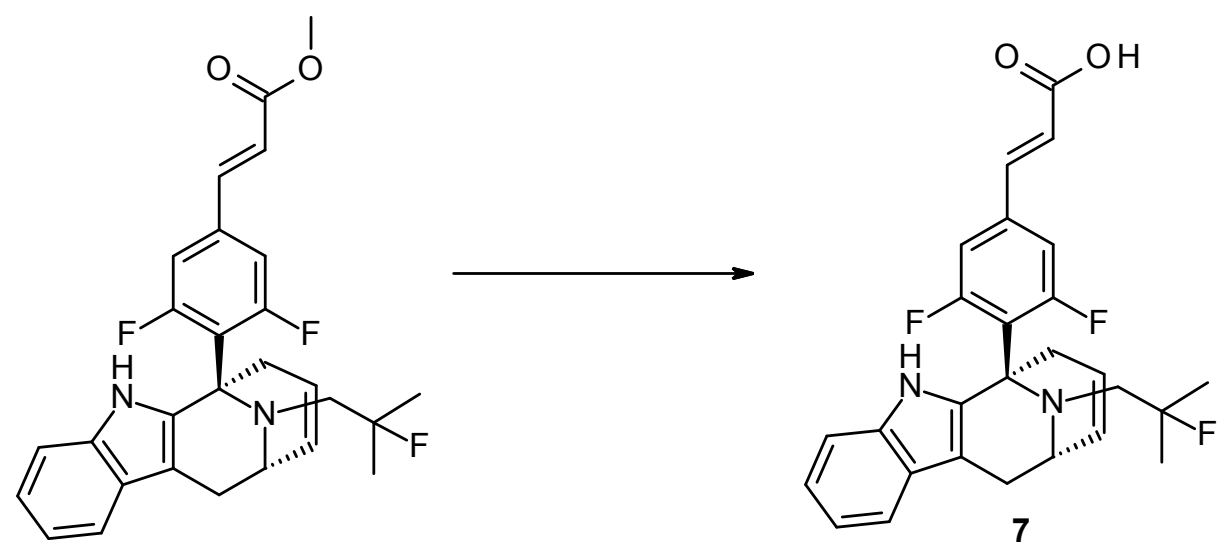

$2 \mathrm{~N} \mathrm{NaOH}$ solution $(0.260 \mathrm{~mL}, 0.52 \mathrm{mmol})$ was added to a solution of methyl $(E)-3$-(3,5-difluoro-4((6R,10S)-12-(2-fluoro-2-methylpropyl)-5,7,10,11-tetrahydro-6H-6,10-epiminocycloocta[b]indol-6-

yl)phenyl)acrylate $(50 \mathrm{mg}, 0.10 \mathrm{mmol})$ in THF $(0.50 \mathrm{~mL}) /$ methanol $(0.50 \mathrm{~mL})$ and the reaction was stirred at room temperature for 1 hour. The reaction was diluted with EtOAc $(10 \mathrm{~mL})$ and water $(10 \mathrm{~mL})$, then the $\mathrm{pH}$ was adjusted to $\sim 5$ by addition of $2 \mathrm{~N} \mathrm{HCl}$ solution. The layers were separated, then the aqueous layer was extracted with EtOAc $(2 \times 10 \mathrm{~mL})$. The combined organics were dried over $\mathrm{Na}_{2} \mathrm{SO}_{4}$, filtered and evaporated. The crude product was purified by flash silica chromatography, elution gradient 0 to $100 \%$ EtOAc in heptane. Pure fractions were evaporated to dryness to afford $(E)-3$-(3,5-difluoro-4-((6R,10S)-12(2-fluoro-2-methylpropyl)-5,7,10,11-tetrahydro-6H-6,10-epiminocycloocta[b]indol-6-yl)phenyl)acrylic acid 7 (44.0 mg, 91\%) as a pale yellow solid. ${ }^{1} \mathrm{H}$ NMR (500 MHz, DMSO-d6, $\left.27{ }^{\circ} \mathrm{C}\right) 1.09(\mathrm{~d}, J=10.2 \mathrm{~Hz}$, $3 \mathrm{H}), 1.13(\mathrm{~d}, J=10.1 \mathrm{~Hz}, 3 \mathrm{H}), 2.39(\mathrm{~m}, 1 \mathrm{H}), 2.52(\mathrm{~m}, 1 \mathrm{H}), 2.60(\mathrm{dd}, J=14.7,1.6 \mathrm{~Hz}, 1 \mathrm{H}), 2.75(\mathrm{t}, J=14.2$ $\mathrm{Hz}, 1 \mathrm{H}), 3.03(\mathrm{dd}, J=14.6,5.2 \mathrm{~Hz}, 1 \mathrm{H}), 3.29(\mathrm{~m}, 1 \mathrm{H}), 3.91(\mathrm{~m}, 1 \mathrm{H}), 5.63(\mathrm{~m}, 1 \mathrm{H}), 5.75(\mathrm{~m}, 1 \mathrm{H}), 6.65(\mathrm{~d}$, $J=16.0 \mathrm{~Hz}, 1 \mathrm{H}), 6.92(\mathrm{dt}, J=7.4,1.3 \mathrm{~Hz}, 1 \mathrm{H}), 6.96(\mathrm{dt}, J=8.0,1.4 \mathrm{~Hz}, 1 \mathrm{H}), 7.13(\mathrm{dt}, J=8.0,1.0 \mathrm{~Hz}$, $1 \mathrm{H}), 7.25(\mathrm{~d}, J=12.2 \mathrm{~Hz}, 1 \mathrm{H}), 7.35(\mathrm{~d}, J=7.6 \mathrm{~Hz}, 1 \mathrm{H}), 7.50(\mathrm{~d}, J=13.7 \mathrm{~Hz}, 1 \mathrm{H}), 7.51(\mathrm{~d}, J=16.0 \mathrm{~Hz}$, 1H), 10.48 (s, 1H), 12.55 (s, 1H); ${ }^{13} \mathrm{C}$ NMR $\left(125 \mathrm{MHz}, \mathrm{DMSO}-\mathrm{d} 6,27{ }^{\circ} \mathrm{C}\right) 23.9$ (d, $\left.J=24.8 \mathrm{~Hz}\right), 25.5(\mathrm{~d}, J$ $=24.1 \mathrm{~Hz}), 26.1,29.1(\mathrm{~d}, J=15.3 \mathrm{~Hz}), 54.7(\mathrm{~d}, J=5.7 \mathrm{~Hz}), 57.1(\mathrm{~d}, J=20.7 \mathrm{~Hz}), 59.9,97.1(\mathrm{~d}, J=166.4$ $\mathrm{Hz}), 105.32,110.96,111.8(\mathrm{~d}, J=41.8 \mathrm{~Hz}), 112.1$ (d, $J=45.5 \mathrm{~Hz}), 117.5,118.1,120.1,122.1,125.3,125.4$, $126.3,126.9,135.7,136.3(\mathrm{t}, J=11.9 \mathrm{~Hz}), 137.9,141.0,161.3,161.5,167.2 ;{ }^{19} \mathrm{~F}$ NMR $(376 \mathrm{MHz}$, DMSOd6, $27{ }^{\circ} \mathrm{C}$ ) -100.5, -109.0, -135.6; HRMS (ESI) for $\mathrm{C}_{27} \mathrm{H}_{25} \mathrm{~F}_{3} \mathrm{~N}_{2} \mathrm{O}_{2}\left(\mathrm{MH}^{+}\right)$; calcd, 467.19409; found 467.19412 .

(6R, 10R)-6-(4-bromo-2,6-difluorophenyl)-12-(2-fluoro-2-methylpropyl)-6,7,8,9,10,11-hexahydro-

\section{$5 \mathrm{H}-6,10-$ epiminocycloocta[b]indole (14)}
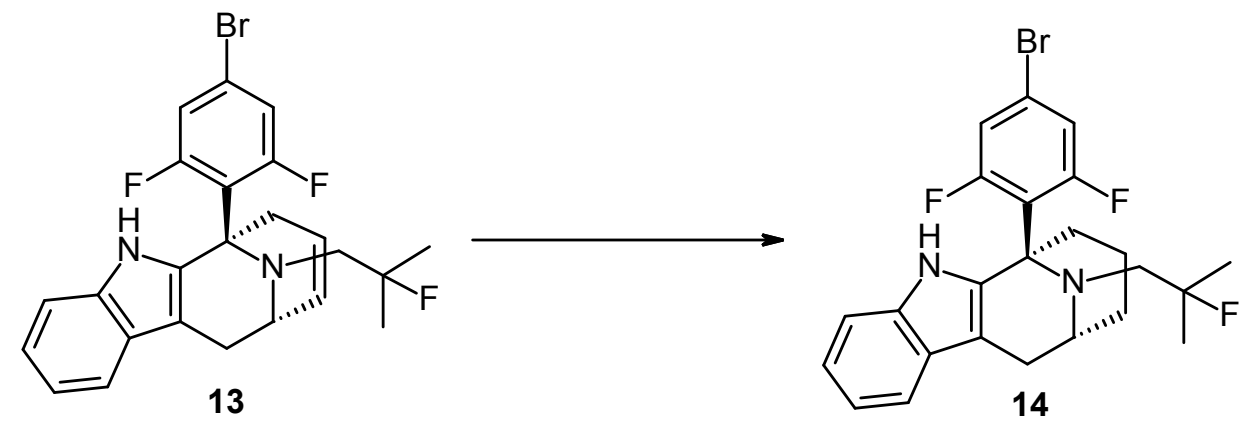

Platinum(IV) oxide (4.35 mg, $0.02 \mathrm{mmol})$ was added to a solution of $(6 R, 10 \mathrm{~S})$-6-(4-bromo-2,6difluorophenyl)-12-(2-fluoro-2-methylpropyl)-6,7,10,11-tetrahydro-5H-6,10-epiminocycloocta[b]indole $13(91 \mathrm{mg}, 0.19 \mathrm{mmol})$ in ethyl acetate $(1.91 \mathrm{~mL})$. The reaction was placed under an atmosphere of hydrogen via balloon and the reaction was stirred at room temperature for 30 minutes. The reaction was filtered and washed with EtOAc. The volatiles were then evaporated to afford $(6 R, 10 R)-6$-(4-bromo-2,6difluorophenyl)-12-(2-fluoro-2-methylpropyl)-6,7,8,9,10,11-hexahydro-5H-6,10epiminocycloocta[b]indole 14 (81 mg, 89\%) as a colourless gum. ${ }^{1} \mathrm{H}$ NMR $\left(500 \mathrm{MHz}, \mathrm{CDCl}_{3}, 27{ }^{\circ} \mathrm{C}\right) 1.12$ 
$(3 \mathrm{H}, \mathrm{d}), 1.15-1.19(3 \mathrm{H}, \mathrm{d}), 1.24-1.29(3 \mathrm{H}, \mathrm{m}), 1.80(1 \mathrm{H}, \mathrm{d}), 2.17(1 \mathrm{H}, \mathrm{t}), 2.44(1 \mathrm{H}, \mathrm{dd}), 2.63(1 \mathrm{H}, \mathrm{d}), 2.67$ $(1 \mathrm{H}, \mathrm{d}), 3.05-3.18(1 \mathrm{H}, \mathrm{m}), 3.35(1 \mathrm{H}, \mathrm{dd}), 3.60(1 \mathrm{H}, \mathrm{t}), 6.93(1 \mathrm{H}, \mathrm{d}), 7.04-7.15(3 \mathrm{H}, \mathrm{m}), 7.18-7.24(2 \mathrm{H}$, m), 7.50-7.57 (1H, m); LRMS for $\mathrm{C}_{24} \mathrm{H}_{24} \mathrm{BrF}_{3} \mathrm{~N}_{2}\left(\mathrm{MH}^{+}\right)$; calcd, 477.1075; nominal mass observed, 477.

(E)-methyl 3-(3,5-difluoro-4-((6R, 10R)-12-(2-fluoro-2-methylpropyl)-6,7,8,9,10,11-hexahydro-5H-

\section{6,10-epiminocycloocta[b]indol-6-yl)phenyl)acrylate}

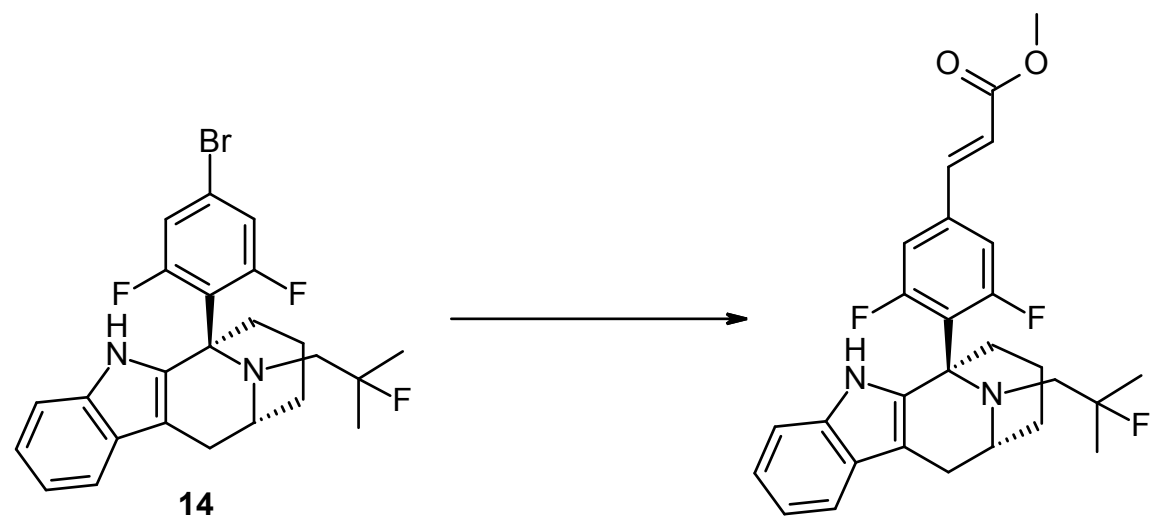

Methyl acrylate (30.6 $\mu \mathrm{l}, \quad 0.34 \mathrm{mmol}),(6 R, 10 R)-6$-(4-bromo-2,6-difluorophenyl)-12-(2-fluoro-2methylpropyl)-6,7,8,9,10,11-hexahydro-5H-6,10-epiminocycloocta[b]indole 14 (81 mg, $0.17 \mathrm{mmol}$ ), Pd $118(5.53 \mathrm{mg}, 8.48 \mu \mathrm{mol})$ and DIPEA $(74.1 \mu 1,0.42 \mathrm{mmol})$ were suspended in degassed 1,4-dioxane (1.59 $\mathrm{mL}$ ) and sealed into a microwave tube. The reaction was heated to $130{ }^{\circ} \mathrm{C}$ for 1 hour in the microwave reactor and cooled to room temperature. The reaction was evaporated to dryness to give a crude product that was purified by flash silica chromatography, elution gradient 0 to $25 \%$ EtOAc in heptane. Pure fractions were evaporated to dryness to afford $(E)$-methyl 3-(3,5-difluoro-4-((6R,10R)-12-(2-fluoro-2methylpropyl)-6,7,8,9,10,11-hexahydro-5H-6,10-epiminocycloocta[b]indol-6-yl)phenyl)acrylate $\quad$ (48.0 $\mathrm{mg}, 59 \%)$ as a yellow crystalline solid. ${ }^{1} \mathrm{H} \mathrm{NMR}\left(500 \mathrm{MHz}, \mathrm{CDCl}_{3}, 27^{\circ} \mathrm{C}\right) 1.11(3 \mathrm{H}, \mathrm{d}), 1.15(3 \mathrm{H}, \mathrm{d}), 1.23$ - $1.29(3 \mathrm{H}, \mathrm{m}), 1.83(1 \mathrm{H}, \mathrm{d}), 2.12-2.24(1 \mathrm{H}, \mathrm{m}), 2.46(1 \mathrm{H}, \mathrm{dd}), 2.68(2 \mathrm{H}, \mathrm{d}), 3.05-3.19(1 \mathrm{H}, \mathrm{m}), 3.37(1 \mathrm{H}$, dd), 3.57-3.66 (1H, m), $3.81(3 \mathrm{H}, \mathrm{s}), 6.41(1 \mathrm{H}, \mathrm{d}), 6.89(1 \mathrm{H}, \mathrm{d}), 7.05(1 \mathrm{H}, \mathrm{d}), 7.08-7.13(2 \mathrm{H}, \mathrm{m}), 7.18$ $7.23(1 \mathrm{H}, \mathrm{m}), 7.24(1 \mathrm{H}, \mathrm{s}), 7.49-7.56(2 \mathrm{H}, \mathrm{m})$; LRMS for $\mathrm{C}_{28} \mathrm{H}_{29} \mathrm{~F}_{3} \mathrm{~N}_{2} \mathrm{O}_{2}\left(\mathrm{MH}^{+}\right)$; calcd, 483.2181; nominal mass observed, 483.

(E)-3-(3,5-difluoro-4-((6R, 10R)-12-(2-fluoro-2-methylpropyl)-6,7,8,9,10,11-hexahydro-5H-6,10epiminocycloocta[b]indol-6-yl)phenyl)acrylic acid (8)

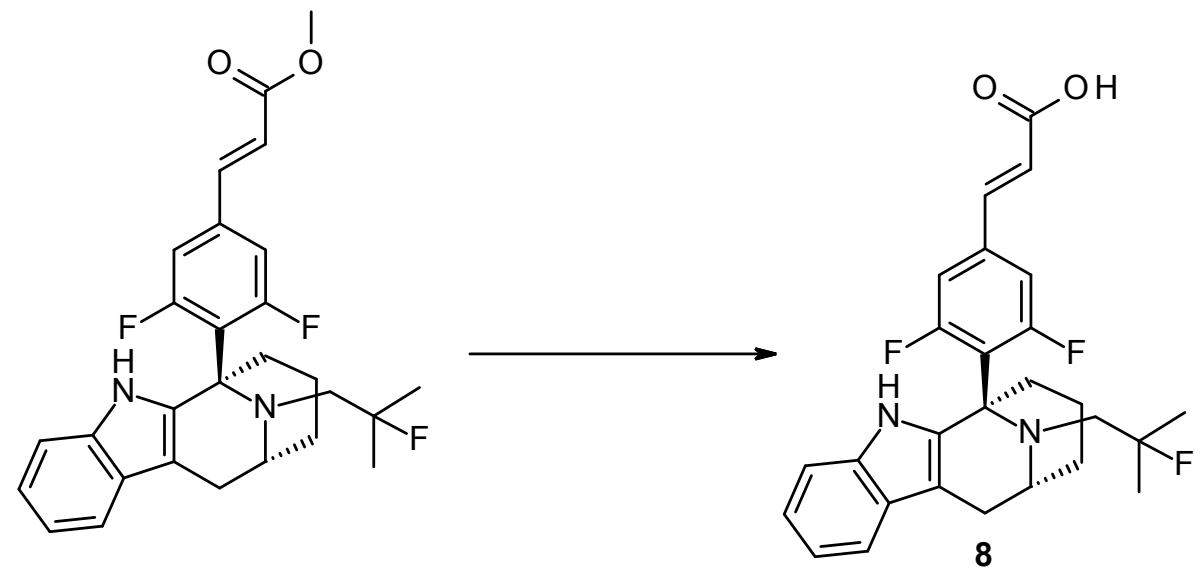

$2 \mathrm{M} \mathrm{NaOH}$ solution $(0.249 \mathrm{~mL}, 0.50 \mathrm{mmol})$ was added to a solution of $(E)$-methyl 3-(3,5-difluoro-4((6R,10R)-12-(2-fluoro-2-methylpropyl)-6,7,8,9,10,11-hexahydro-5H-6,10-epiminocycloocta[b]indol-6yl)phenyl)acrylate $(48 \mathrm{mg}, 0.10 \mathrm{mmol})$ in THF $(1 \mathrm{~mL}) / \mathrm{MeOH}(0.500 \mathrm{~mL})$. The resulting solution was 
stirred at $20{ }^{\circ} \mathrm{C}$ for 2 hours. The crude product was purified by ion exchange chromatography, using an SCX-2 column. The desired product was eluted from the column using $7 \mathrm{M} \mathrm{NH}_{3} / \mathrm{MeOH}$ and pure fractions were evaporated to dryness to afford (E)-3-(3,5-difluoro-4-((6R,10R)-12-(2-fluoro-2-methylpropyl)6,7,8,9,10,11-hexahydro-5H-6,10-epiminocycloocta[b]indol-6-yl)phenyl)acrylic acid 8 (42.0 $\mathrm{mg}, 90 \%)$ as pale yellow solid. ${ }^{1} \mathrm{H}$ NMR $\left(500 \mathrm{MHz}\right.$, DMSO-d6, $\left.27^{\circ} \mathrm{C}\right) 0.97(\mathrm{~m}, 1 \mathrm{H}), 1.05(\mathrm{~d}, J=21.7 \mathrm{~Hz}, 3 \mathrm{H}), 1.05(\mathrm{~d}$, $J=21.7 \mathrm{~Hz}, 3 \mathrm{H}), 1.20(\mathrm{~m}, 1 \mathrm{H}), 1.46(\mathrm{~m}, 1 \mathrm{H}), 1.78(\mathrm{~m}, 1 \mathrm{H}), 2.13(\mathrm{~m}, 1 \mathrm{H}), 2.42(\mathrm{dd}, \mathrm{J}=26.5,14.8 \mathrm{~Hz}, 1 \mathrm{H})$, $2.56(\mathrm{~m}, 1 \mathrm{H}), 2.63(\mathrm{~d}, J=14.4 \mathrm{~Hz}, 1 \mathrm{H}), 3.11(\mathrm{t}, J=15.0 \mathrm{~Hz}, 1 \mathrm{H}), 3.18(\mathrm{dd}, J=15.0,5.9 \mathrm{~Hz}, 1 \mathrm{H}), 3.48(\mathrm{~m}$, $1 \mathrm{H}), 6.65(\mathrm{~d}, J=16.0 \mathrm{~Hz}, 1 \mathrm{H}), 6.94(\mathrm{dt}, J=7.0,1.3 \mathrm{~Hz}, 1 \mathrm{H}), 6.97(\mathrm{dt}, J=7.0,1.4 \mathrm{~Hz}, 1 \mathrm{H}), 7.15(\mathrm{~m}, 1 \mathrm{H})$, $7.21(\mathrm{~d}, J=12.1 \mathrm{~Hz}, 1 \mathrm{H}), 7.40(\mathrm{dd}, J=7.0,1.3 \mathrm{~Hz}, 1 \mathrm{H}), 7.40(\mathrm{~d}, J=12.1 \mathrm{~Hz}, 1 \mathrm{H}), 7.42(\mathrm{~d}, J=16.0 \mathrm{~Hz}$, 1H), 10.37 (s, 1H); ${ }^{19} \mathrm{~F}$ NMR (376 MHz, DMSO-d6, $\left.27{ }^{\circ} \mathrm{C}\right)$-100.9, -108.6, -137.3; HRMS (ESI) for $\mathrm{C}_{27} \mathrm{H}_{27} \mathrm{~F}_{3} \mathrm{~N}_{2} \mathrm{O}_{2}\left(\mathrm{MH}^{+}\right)$; calcd, 469.20974; found, 469.21002 .

(6R,10R)-6-(2,6-difluoro-4-(2-(3-(fluoromethyl)azetidin-1-yl)ethoxy)phenyl)-12-(2-fluoro-2methylpropyl)-6,7,8,9,10,11-hexahydro-5H-6,10-epiminocycloocta[b]indole (17)

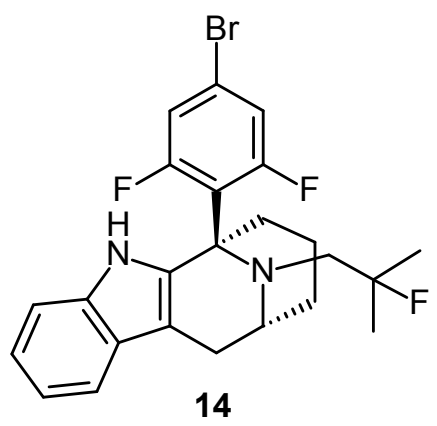

RockPhos $3^{\text {rd }}$ generation precatalyst $(4.13 \mathrm{mg}, 4.92 \mu \mathrm{mol})$ was added in one portion to 2-(3(fluoromethyl)azetidin-1-yl)ethan-1-ol (39.3 mg, $0.30 \mathrm{mmol}),(6 R, 10 R)-6$-(4-bromo-2,6-difluorophenyl)12-(2-fluoro-2-methylpropyl)-6,7,8,9,10,11-hexahydro-5H-6,10-epiminocycloocta[b]indole 14 (47 mg, $0.10 \mathrm{mmol})$ and cesium carbonate $(64.2 \mathrm{mg}, 0.20 \mathrm{mmol})$ in toluene $(1 \mathrm{~mL})$ under nitrogen. The resulting solution was stirred at $90^{\circ} \mathrm{C}$ for 4 hours. The reaction mixture was diluted with water $(10 \mathrm{~mL})$ and extracted with EtOAc $(2 \times 10 \mathrm{~mL})$. The organics were combined, dried with $\mathrm{MgSO}_{4}$, filtered and evaporated to afford crude product that was purified by flash silica chromatography, elution gradient 0 to $5 \% \mathrm{MeOH}$ in DCM. Pure fractions were evaporated to dryness to afford (6R,10R)-6-(2,6-difluoro-4-(2-(3(fluoromethyl)azetidin-1-yl)ethoxy)phenyl)-12-(2-fluoro-2-methylpropyl)-6,7,8,9,10,11-hexahydro-5H6,10-epiminocycloocta[b]indole $17(13.0 \mathrm{mg}, 25 \%)$ as a cream solid. ${ }^{1} \mathrm{H}$ NMR (500 MHz, DMSO-d6, 27 $\left.{ }^{\circ} \mathrm{C}\right) 0.95(\mathrm{~m}, 1 \mathrm{H}), 1.06(\mathrm{~d}, J=21.5 \mathrm{~Hz}, 6 \mathrm{H}), 1.20(\mathrm{~m}, 1 \mathrm{H}), 1.44(\mathrm{~m}, 1 \mathrm{H}), 1.73(\mathrm{~m}, 1 \mathrm{H}), 2.12(\mathrm{~m}, 1 \mathrm{H}), 2.42$ $(\mathrm{m}, 1 \mathrm{H}), 2.52(\mathrm{~m} .1 \mathrm{H}), 2.60(\mathrm{~d}, J=14.0 \mathrm{~Hz}, 1 \mathrm{H}), 2.71(\mathrm{~m}, 2 \mathrm{H}), 2.74(\mathrm{~m}, 1 \mathrm{H}), 2.98(\mathrm{~m}, 2 \mathrm{H}), 3.07(\mathrm{t}, J=$ $15.0 \mathrm{~Hz}, 1 \mathrm{H}), 3.16(\mathrm{dd}, J=15.0,5.9 \mathrm{~Hz}, 1 \mathrm{H}), 3.31(\mathrm{~m}, 2 \mathrm{H}), 3.48(\mathrm{t}, J=5.9 \mathrm{~Hz}, 1 \mathrm{H}), 3.92(\mathrm{~m}, 2 \mathrm{H}), 4.50$ $(\mathrm{dd}, J=47.6,6.2 \mathrm{~Hz}, 2 \mathrm{H}), 6.47(\mathrm{~d}, J=13.3,1 \mathrm{H}), 6.67(\mathrm{~d}, J=14.7,1 \mathrm{H}), 6.94(\mathrm{~m}, 2 \mathrm{H}), 7.15(\mathrm{~m}, 1 \mathrm{H}), 7.38$ $(\mathrm{m}, 1 \mathrm{H}), 10.31(\mathrm{~s}, 1 \mathrm{H}) ;{ }^{13} \mathrm{C}$ NMR $\left(125 \mathrm{MHz}, \mathrm{DMSO}-\mathrm{d} 6,2{ }^{\circ} \mathrm{C}\right) 19.0(\mathrm{~d}, J=3.7 \mathrm{~Hz}), 22.6,23.9(\mathrm{~d}, J=24.6$ $\mathrm{Hz}), 25.2(J=24.1 \mathrm{~Hz}), 27.7,30.7(\mathrm{~d}, J=19.9 \mathrm{~Hz}), 40.4,52.2(\mathrm{~d}, J=4.2 \mathrm{~Hz}), 55.8(\mathrm{~d}, J=22.5 \mathrm{~Hz}), 56.0$, 56.1, 56.9, $60.9(\mathrm{~d}, J=4.1 \mathrm{~Hz}), 67.2,84.6(\mathrm{~d}, J=163.7 \mathrm{~Hz}), 97.1(\mathrm{~d}, J=166.2 \mathrm{~Hz}), 98.5(\mathrm{~d}, J=30.3 \mathrm{~Hz})$, $99.8(\mathrm{~d}, J=27.7 \mathrm{~Hz}), 107.0(\mathrm{~d}, J=2.7 \mathrm{~Hz}), 110.8(\mathrm{~d}, J=13.3 \mathrm{~Hz}), 110.9,117.4,118.0,119.8,126.1,135.8$, $137.5,159.3(\mathrm{~d}, J=15.6 \mathrm{~Hz}), 162.7(\mathrm{dd}, \mathrm{J}=252.0,13.1 \mathrm{~Hz}), 163.3(\mathrm{dd}, \mathrm{J}=246.0,10.1 \mathrm{~Hz}) ;{ }^{19} \mathrm{~F}$ NMR $(376$ MHz, DMSO-d6, $27{ }^{\circ} \mathrm{C}$ ) -100.2, -107.6, -137.3, -219.8; HRMS (ESI) for $\mathrm{C}_{30} \mathrm{H}_{35} \mathrm{~F}_{4} \mathrm{~N}_{3} \mathrm{O}\left(\mathrm{MH}^{+}\right.$); calcd, 530.27890; found 530.27857.

\section{(1R,3R)-1-(2,6-difluoro-4-(2-(3-(fluoromethyl)azetidin-1-yl)ethoxy)phenyl)-2-(2-fluoro-2-}

methylpropyl)-3-methyl-2,3,4,9-tetrahydro-1H-pyrido[3,4-b]indole (15) 

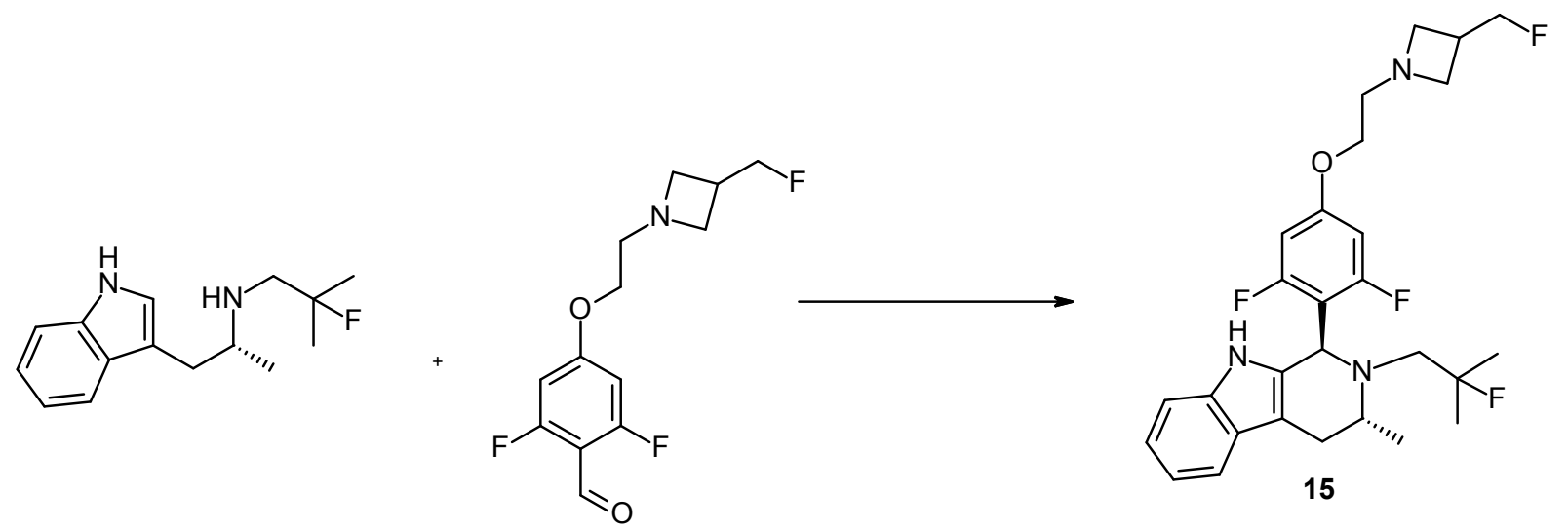

$(R)-N$-(1-(1H-indol-3-yl)propan-2-yl)-2-fluoro-2-methylpropan-1-amine (40 $\mathrm{mg}, 0.16 \mathrm{mmol})$ and 2,6difluoro-4-(2-(3-(fluoromethyl)azetidin-1-yl)ethoxy)benzaldehyde (46.2 $\mathrm{mg}, 0.17 \mathrm{mmol}$ ) were dissolved in toluene $(1.5 \mathrm{~mL})$ and treated with $\mathrm{AcOH}(0.167 \mathrm{~mL})$. The reaction was heated at $80{ }^{\circ} \mathrm{C}$ for $6 \mathrm{hrs}$. The reaction was diluted with EtOAc $(15 \mathrm{~mL})$ and quenched with saturated $\mathrm{NaHCO}_{3}$ solution $(15 \mathrm{~mL})$. The layers were separated and the organic layer was dried over $\mathrm{Na}_{2} \mathrm{SO}_{4}$, filtered, and evaporated. The crude residue was purified by preparative HPLC chromatography (Xbridge phenyl column, $\mathrm{MeCN} / \mathrm{H}_{2} \mathrm{O}$ containing $\left.\mathrm{NH}_{4} \mathrm{OH}, 60-80 \%\right)$ to afford (1R,3R)-1-(2,6-difluoro-4-(2-(3-(fluoromethyl)azetidin-1yl)ethoxy)phenyl)-2-(2-fluoro-2-methylpropyl)-3-methyl-2,3,4,9-tetrahydro-1H-pyrido[3,4-b]indole 15 as a solid. ${ }^{1} \mathrm{H}$ NMR $\left(500 \mathrm{MHz}, \mathrm{DMSO}-\mathrm{d} 6,27{ }^{\circ} \mathrm{C}\right) 1.04(\mathrm{~d}, J=6.5 \mathrm{~Hz}, 3 \mathrm{H}), 1.14(\mathrm{~d}, J=29.0,3 \mathrm{H}), 1.18(\mathrm{~d}, J$ $=29.4,3 \mathrm{H}), 2.34(\mathrm{dd}, J=24.0,15.0 \mathrm{~Hz}, 1 \mathrm{H}), 2.52(\mathrm{~m}, 1 \mathrm{H}), 2.55(\mathrm{dd}, \mathrm{J}=15.1,5.0 \mathrm{~Hz}, 1 \mathrm{H}), 2.70(\mathrm{t}, J=5.4$ $\mathrm{Hz}, 2 \mathrm{H}), 2.73(\mathrm{~m}, 1 \mathrm{H}), 2.83(\mathrm{dd}, J=20.7,15.0 \mathrm{~Hz}, 1 \mathrm{H}), 2.88(\mathrm{~m}, 1 \mathrm{H}), 2.99(\mathrm{t}, J=6.6 \mathrm{~Hz}, 2 \mathrm{H}), 3.30(\mathrm{~m}$, $1 \mathrm{H}), 3.51(\mathrm{~m}, 1 \mathrm{H}), 3.93(\mathrm{t}, J=5.5 \mathrm{~Hz}, 2 \mathrm{H}), 4.50(\mathrm{dd}, J=47.6,6.2 \mathrm{~Hz}, 2 \mathrm{H}), 5.12(\mathrm{~s}, 1 \mathrm{H}), 6.64(\mathrm{~m}, 2 \mathrm{H}), 6.94$ $(\mathrm{dt}, J=7.4,1.2 \mathrm{~Hz}, 1 \mathrm{H}), 6.99(\mathrm{dt}, \mathrm{J}=8.0,1.3 \mathrm{~Hz}, 1 \mathrm{H}), 7.18(\mathrm{~d}, J=7.9 \mathrm{~Hz}, 1 \mathrm{H}), 7.39(\mathrm{~d}, J=7.7 \mathrm{~Hz}, 1 \mathrm{H})$, $10.51(\mathrm{~s}, 1 \mathrm{H}) ;{ }^{13} \mathrm{C}$ NMR $\left(125 \mathrm{MHz}, \mathrm{DMSO}-\mathrm{d} 6,27{ }^{\circ} \mathrm{C}\right) 24.5(\mathrm{~d}, J=24.5 \mathrm{~Hz}), 24.8(\mathrm{~d}, J=24.5 \mathrm{~Hz}), 26.6$, 30.6, 30.8, 50.5, 55.6, 56.0 (2C), 56.1, 56.9, 67.2, $84.6(\mathrm{~d}, J=163.7 \mathrm{~Hz}), 97.0(\mathrm{~d}, J=248 \mathrm{~Hz}), 98.7(\mathrm{~d}, J=$ $26.4 \mathrm{~Hz}, 2 \mathrm{C}), 106.3,109.2(\mathrm{t}, J=15.5 \mathrm{~Hz}), 110.9,117.4,118.1,120.3,126.9,132.6,136.2,159.5(\mathrm{t}, J=$ $14.9 \mathrm{~Hz}), 162.21(\mathrm{~d}, \mathrm{~J}=247.7 \mathrm{~Hz}, 2 \mathrm{C}) ;{ }^{19} \mathrm{~F}$ NMR (376 MHz, DMSO-d6, $\left.27{ }^{\circ} \mathrm{C}\right)-111.0,-137.2$, -219.8; HRMS (ESI) for $\mathrm{C}_{28} \mathrm{H}_{33} \mathrm{~F}_{4} \mathrm{~N}_{3} \mathrm{O}\left(\mathrm{MH}^{+}\right)$; calcd, 504.26325; found 504.26345.

\section{(1R,3R)-1-(4-bromo-2,6-difluorophenyl)-2-(2-fluoro-2-methylpropyl)-1,3-dimethyl-2,3,4,9- tetrahydro-1H-pyrido[3,4-b]indole}<smiles>C[C@H]1Cc2c([nH]c3ccccc23)[C@@H](c2c(F)cc(Br)cc2F)N1CC(C)(C)F</smiles>

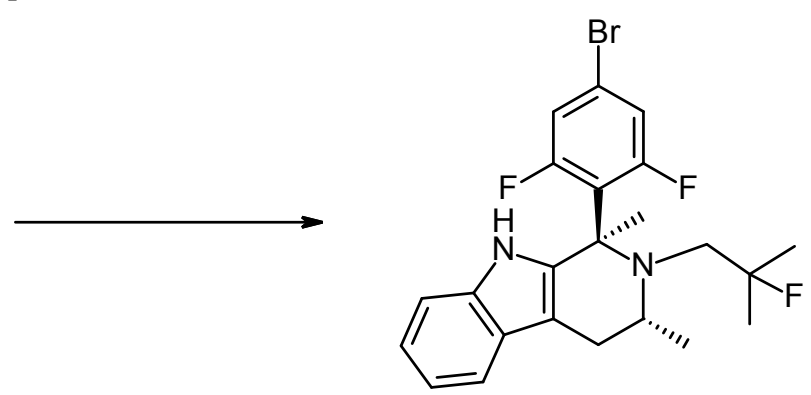

Ceric ammonium nitrate $(2.73 \mathrm{~g}, 4.99 \mathrm{mmol})$ was added to a solution of $(1 R, 3 R)$-1-(4-bromo-2,6difluorophenyl)-2-(2-fluoro-2-methylpropyl)-3-methyl-2,3,4,9-tetrahydro-1H-pyrido[3,4-b]indole (1.00 g, $2.22 \mathrm{mmol})$ in acetonitrile $(12.05 \mathrm{ml})$ / water $(3.01 \mathrm{ml})$ and the reaction was stirred at room temperature for 2 hours. EtOAc and brine were added and the layers were separated. The aqueous layer was extracted with EtOAc, then the combined organics were dried and evaporated. The crude residue (iminium ion) was dissolved in THF $(15 \mathrm{~mL})$ and cooled to $-78{ }^{\circ} \mathrm{C}$. Methylmagnesium bromide $(2.66 \mathrm{ml}, 6.65 \mathrm{mmol})$ was added and the reaction was stirred for 1 hour, then was quenched by addition of $\mathrm{NH}_{4} \mathrm{Cl}$ solution. The mixture was extracted with EtOAc, then the organics were dried and evaporated. The crude product was purified by flash silica chromatography, elution gradient 0 to $25 \%$ EtOAc in heptane. Pure fractions were 
evaporated to dryness to afford (1R,3R)-1-(4-bromo-2,6-difluorophenyl)-2-(2-fluoro-2-methylpropyl)-1,3dimethyl-2,3,4,9-tetrahydro-1H-pyrido[3,4-b]indole $(0.145 \mathrm{~g}, 14 \%)$ as a pale yellow solid. LRMS for $\mathrm{C}_{23} \mathrm{H}_{24} \mathrm{BrF}_{3} \mathrm{~N}_{2}\left(\mathrm{MH}^{+}\right)$; calcd, 465.1075; nominal mass observed, 465.

\section{(1R,3R)-1-(2,6-difluoro-4-(2-(3-(fluoromethyl)azetidin-1-yl)ethoxy)phenyl)-2-(2-fluoro-2-}

\section{methylpropyl)-1,3-dimethyl-2,3,4,9-tetrahydro-1H-pyrido[3,4-b]indole (16)}

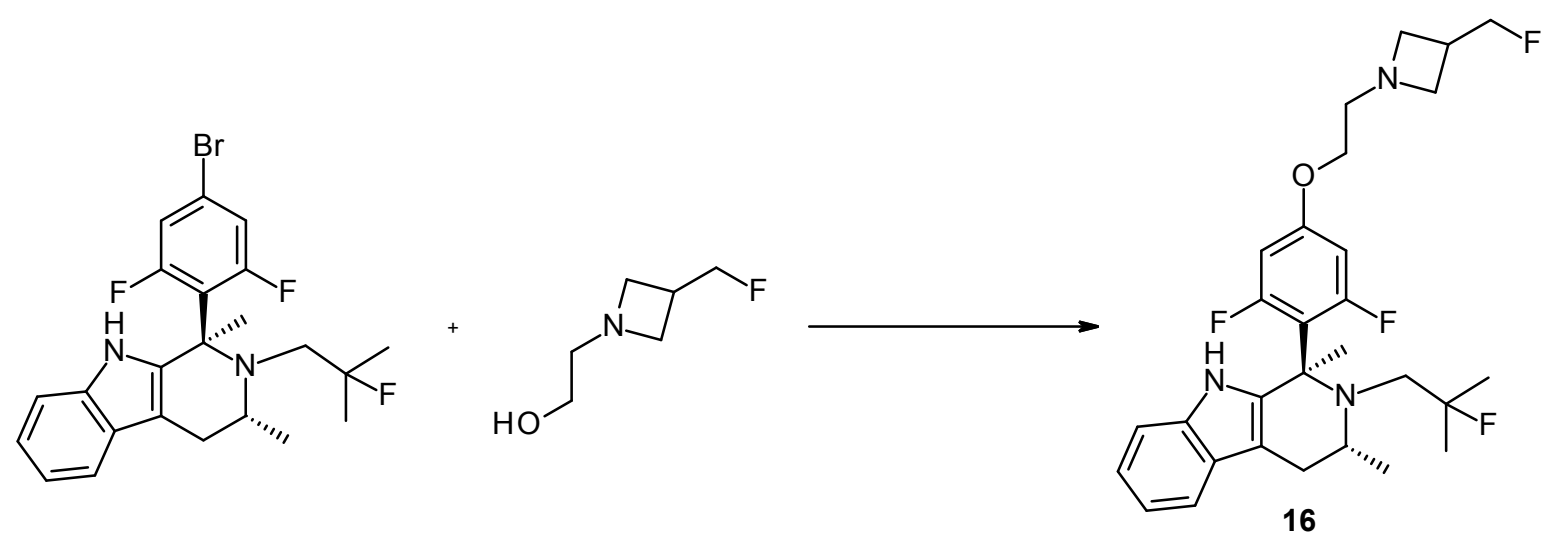

Rockphos 3rd generation precatalyst $(12.4 \mathrm{mg}, 0.02 \mathrm{mmol})$ was added to a suspension of (1R,3R)-1-(4bromo-2,6-difluorophenyl)-2-(2-fluoro-2-methylpropyl)-1,3-dimethyl-2,3,4,9-tetrahydro-1H-pyrido[3,4b]indole (140 mg, $0.30 \mathrm{mmol}), 2$-(3-(fluoromethyl)azetidin-1-yl)ethan-1-ol (80 mg, $0.60 \mathrm{mmol}$ ) and cesium carbonate $(196 \mathrm{mg}, 0.60 \mathrm{mmol})$ in degassed toluene $(2.41 \mathrm{~mL})$ and the reaction was heated to $90{ }^{\circ} \mathrm{C}$ overnight. After cooling, the reaction was diluted with DCM $(25 \mathrm{~mL})$ and water $(25 \mathrm{~mL})$ and the layers were separated. The aqueous layer was extracted with DCM $(25 \mathrm{~mL})$, then the combined organics were dried over $\mathrm{Na}_{2} \mathrm{SO}_{4}$, filtered and evaporated. The crude product was purified by flash silica chromatography, elution gradient 0 to $100 \%$ EtOAc in heptane. Pure fractions were evaporated to dryness to afford $(1 R, 3 R)$ 1-(2,6-difluoro-4-(2-(3-(fluoromethyl)azetidin-1-yl)ethoxy)phenyl)-2-(2-fluoro-2-methylpropyl)-1,3dimethyl-2,3,4,9-tetrahydro-1H-pyrido[3,4-b]indole $16(129 \mathrm{mg}, 83 \%)$ as a beige solid. ${ }^{1} \mathrm{H}$ NMR (500 MHz, DMSO-d6, $\left.27^{\circ} \mathrm{C}\right) 0.99(\mathrm{~d}, J=21.6 \mathrm{~Hz}, 3 \mathrm{H}), 1.07(\mathrm{~d}, J=6.7 \mathrm{~Hz}, 3 \mathrm{H}), 1.18(\mathrm{~d}, J=21.4 \mathrm{~Hz}, 3 \mathrm{H}), 1.81$ (s, 3H), $2.62(\mathrm{dd}, J=14.7,3.6 \mathrm{~Hz}, 2 \mathrm{H}), 2.68(\mathrm{~m}, 2 \mathrm{H}), 2.73(\mathrm{~m}, 1 \mathrm{H}), 2.86(\mathrm{dd}, J=14.7,5.4 \mathrm{~Hz}, 1 \mathrm{H}), 2.96$ $(\mathrm{m}, 2 \mathrm{H}), 2.98(\mathrm{~m}, 1 \mathrm{H}), 3.28(\mathrm{~m}, 2 \mathrm{H}), 3.65(\mathrm{~m}, 1 \mathrm{H}), 3.89(\mathrm{~m}, 2 \mathrm{H}), 4.49(\mathrm{dd}, J=47.6,6.2 \mathrm{~Hz}, 2 \mathrm{H}), 6.51(\mathrm{~d}$, $J=13.1 \mathrm{~Hz}, 2 \mathrm{H}), 6.94(\mathrm{~d}, J=7.5 \mathrm{~Hz}, 1 \mathrm{H}), 7.00(\mathrm{~d}, J=7.2 \mathrm{~Hz}, 1 \mathrm{H}), 7.20(\mathrm{~d}, J=7.9 \mathrm{~Hz}, 1 \mathrm{H}), 7.40(\mathrm{~d}, J=$ $7.7 \mathrm{~Hz}, 1 \mathrm{H}), 10.64(\mathrm{~s}, 1 \mathrm{H}) ;{ }^{13} \mathrm{C}$ NMR $\left(125 \mathrm{MHz}, \mathrm{DMSO}-\mathrm{d} 6,27{ }^{\circ} \mathrm{C}\right) 17.3,24.2(\mathrm{~d}, J=24.9 \mathrm{~Hz}), 25.2,26.2$ $(\mathrm{d}, J=24.9 \mathrm{~Hz}), 27.1,31.2(\mathrm{~d}, J=19.9 \mathrm{~Hz}), 50.8(\mathrm{~d}, J=5.3 \mathrm{~Hz}), 53.78(\mathrm{~d}, J=21.1 \mathrm{~Hz}), 56.5,56.6,57.4$, 60.4, 67.6, 85.1 (d, $J=163.7 \mathrm{~Hz}), 97.7(\mathrm{~d}, J=167.2 \mathrm{~Hz}), 99.5(\mathrm{~d}, J=29.4 \mathrm{~Hz}, 2 \mathrm{C}), 104.6,111.3,114.9$, 118.1, 118.5, 120.7, 127.2, 136.5, 138.9, $159.0(\mathrm{~d}, J=15.7 \mathrm{~Hz}), 162.5(\mathrm{~d}, J=248.8 \mathrm{~Hz}, 2 \mathrm{C}) ;{ }^{19} \mathrm{~F}$ NMR $(376$ MHz, DMSO-d6, $27^{\circ} \mathrm{C}$ ) -106.1, -133.8, -219.9; HRMS (ESI) for $\mathrm{C}_{29} \mathrm{H}_{35} \mathrm{~F}_{4} \mathrm{~N}_{3} \mathrm{O}\left(\mathrm{MH}^{+}\right)$; calcd, 518.27890; found 518.27918 .

\section{Biochemical Results:}

Assays were run as per Callis R.; Rabow A.; Tonge M.; Bradbury R.; Challinor M.; Roberts K.; Jones K.; Walker G. A Screening Assay Cascade to Identify and Characterize Novel Selective Estrogen Receptor Downregulators (SERDs). J. Biomol. Screen. 2015, 20(6),748-759 and are fully described below

\section{ER $\alpha$ binding assay}

The ability of compounds to bind to isolated Estrogen Receptor Alpha Ligand binding domain (ER alpha LBD (GST)) was assessed in competition assays using a LanthaScreen ${ }^{\mathrm{TM}}$ Time-Resolved Fluorescence Resonance Energy Transfer (TR-FRET) detection end-point. For the LanthaScreen TR-FRET endpoint, a suitable fluorophore (Fluormone ES2, Product code P2645) and recombinant human Estrogen Receptor alpha ligand binding domain (Product code PV4543) were purchased from Invitrogen and used to measure 
compound binding. The assay principle is that ER alpha -LBD (GST) is added to a fluorescent ligand to form a receptor/fluorophore complex. A terbium-labelled anti-GST antibody (Product code PV3551) is used to indirectly label the receptor by binding to its GST tag, and competitive binding is detected by a test compounds' ability to displace the fluorescent ligand resulting in a loss of TR-FRET signal between the $\mathrm{Tb}$-anti-GST antibody and the tracer. The assay was performed as follows with all reagent additions carried out using the Beckman Coulter BioRAPTR FRD microfluidic workstation:-

1. Acoustic dispense $120 \mathrm{nl}$ of the test compound into a black low volume 384 well assay plates.

2. Prepare 1x ER alpha-LBD/Tb-antiGST Ab in ES2 screening buffer and incubate for 20 minutes.

3. Add 1x fluorophore to the ER alpha-LBD/Tb-antiGST Ab solution prior to use.

4. Dispense $12 \mu \mathrm{l}$ of the $1 \mathrm{x}$ AR-LBD/Tb-anti-GST Ab/Fluorophore reagent into each well of the assay plate

5. Cover the assay plate to protect the reagents from light and evaporation, and incubate at room temperature for 1 hour.

6. Excite at $337 \mathrm{~nm}$ and measure the fluorescent emission signal of each well at $490 \mathrm{~nm}$ and $520 \mathrm{~nm}$ using the BMG PheraSTAR.

Compounds were dosed directly from a compound source microplate containing serially diluted compound (4 wells containing $10 \mathrm{mM}, 0.1 \mathrm{mM}, 1 \mu \mathrm{M}$ and $10 \mathrm{nM}$ final compound respectively) to an assay microplate using the Labcyte Echo 550. The Echo 550 is a liquid handler that uses acoustic technology to perform direct microplate-to-microplate transfers of DMSO compound solutions and the system can be programmed to transfer multiple small $\mathrm{nL}$ volumes of compound from the different source plate wells to give the desired serial dilution of compound in the assay which is then back-filled to normalise the DMSO concentration across the dilution range. In total $120 \mathrm{~nL}$ of compound plus DMSO is added to each well and compounds were tested in a 12-point concentration response format over a final compound concentration range of 100, $29.17,10.42,2.083,1,0.292,0.104,0.02083,0.01,0.002917,0.001042,0.0001 \mu \mathrm{M}$, respectively. TRFRET dose response data obtained with each compound was exported into a suitable software package (such as Origin or Genedata) to perform curve fitting analysis. Competitive ER alpha binding was expressed as an $\mathrm{IC}_{50}$ value. This was determined by calculation of the concentration of compound that was required to give a $50 \%$ reduction in tracer compound binding to ER alpha-LBD.

\section{MCF-7 ER degradation assay}

The ability of compounds to down-regulate Estrogen Receptor (ER) numbers was assessed in a cell based immuno-fluorescence assay using the MCF-7 human ductal carcinoma breast cell line. MCF-7 cells were revived directly from a cryovial (approx 5 x $10^{6}$ cells) in Assay Medium (phenol red free Dulbecco's Modified Eagle's medium (DMEM) (Sigma D5921) containing 2mM L-Glutamine and 5\% (v/v) Charcoal/Dextran treated foetal calf serum Cells were syringed once using a sterile $18 \mathrm{G} \times 1.5 \mathrm{inch}(1.2 \mathrm{x}$ $40 \mathrm{~mm}$ ) broad gauge needle and cell density was measured using a Coulter Counter (Beckman). Cells were further diluted in Assay Medium to a density of 3.75x $10^{4}$ cells per $\mathrm{ml}$ and $40 \mu \mathrm{l}$ per well added to transparent bottomed, black, tissue culture treated 384 well plates (Costar, No. 3712) using a Thermo Scientific Matrix WellMate or Thermo Multidrop. Following cell seeding, plates were incubated overnight at $37{ }^{\circ} \mathrm{C}, 5 \% \mathrm{CO}_{2}$ (Liconic carousel incubator). Test data was generated using the LabCyte Echo ${ }^{\circledR}$ model 555 compound reformatter which is part of an automated workcell (Integrated Echo 2 workcell). $10 \mathrm{mM}$ compound stock solutions of the test compounds were used to generate a 384 well compound dosing plate (Labcyte P-05525CV1). $40 \mu \mathrm{l}$ of each of the $10 \mathrm{mM}$ compound stock solutions was dispensed into the first quadrant well and then 1:100 step-wise serial dilutions in DMSO were performed using a Hydra II (MATRIX UK) liquid handling unit to give $40 \mathrm{ul}$ of diluted compound into quadrant wells $2(0.1 \mathrm{mM}), 3(1 \mu \mathrm{M})$ and $4(0.01 \mu \mathrm{M})$, respectively. $40 \mu \mathrm{l}$ of DMSO added to wells in row $\mathrm{P}$ on the source plate allow for DMSO normalisation across the dose range. To dose the control wells $40 \mu \mathrm{l}$ of DMSO was added to row $\mathrm{O} 1$ and $40 \mu 1$ of $100 \mu \mathrm{M}$ Faslodex ${ }^{\circledR}$ in DMSO was added to row O3 on the compound source plate. The Echo uses acoustic technology to perform direct microplate-to-microplate transfers of DMSO compound solutions to assay plates. The system can be programmed to transfer volumes as low as $2.5 \mathrm{~nL}$ in multiple increments between microplates and in so doing generates a serial dilution of compound in the assay plate which is then backfilled to normalise the DMSO concentration across the dilution range. Compounds were dispensed onto the cell plates with a compound source plate prepared as above producing a $12 \mathrm{pt}$ duplicate $3 \mu \mathrm{M}$ to $3 \mathrm{pM}$ dose 
range with 3 fold dilutions and one final 10 fold dilution using the Integrated Echo 2 workcell. The maximum signal control wells were dosed with DMSO to give a final concentration of $0.3 \%$ and the minimum signal control wells were dosed with Faslodex ${ }^{\circledR}$ to give a final concentration of $100 \mathrm{nM}$ accordingly. Plates were further incubated for $18-22$ hours at $37{ }^{\circ} \mathrm{C}, 5 \% \mathrm{CO}_{2}$ and then fixed by the addition of $20 \mu \mathrm{l}$ of $11.1 \%(\mathrm{v} / \mathrm{v})$ formaldehyde solution (in phosphate buffered saline (PBS)) giving a final formaldehyde concentration of 3.7\% (v/v). Cells were fixed at room temperature for 20 mins before being washed two times with $250 \mu 1 \mathrm{PBS} /$ Proclin (PBS with a Biocide preservative) using a BioTek platewasher, $40 \mu \mathrm{l}$ of PBS/Proclin was then added to all wells and the plates stored at $4{ }^{\circ} \mathrm{C}$. The fixing method described above was carried out on the Integrated Echo 2 workcell. Immunostaining was performed using an automated AutoElisa workcell. The PBS/Proclin was aspirated from all wells and the cells permeabilised with $40 \mu \mathrm{l}$ PBS containing $0.5 \%$ Tween ${ }^{\mathrm{TM}} 20(\mathrm{v} / \mathrm{v})$ for 1 hour at room temperature. The plates were washed three times in $250 \mu \mathrm{l}$ of PBS/0.05\% (v/v) Tween 20 with Proclin (PBST with a Biocide preservative) and then $20 \mu \mathrm{l}$ of ER $\alpha$ (SP1) Rabbit monoclonal antibody (Thermofisher) 1:1000 in PBS/Tween ${ }^{\mathrm{TM}} / 3 \%(\mathrm{w} / \mathrm{v})$ Bovine Serum Albumin was added. The plates were incubated overnight at $4{ }^{\circ} \mathrm{C}$ (Liconic carousel incubator) and then washed three times in $250 \mu \mathrm{l}$ of PBS $/ 0.05 \%(\mathrm{v} / \mathrm{v})$ Tween ${ }^{\mathrm{TM}} 20$ with Proclin (PBST). The plates were then incubated with $20 \mu \mathrm{l} /$ well of a goat anti-rabbit IgG AlexaFluor 594 or goat anti-rabbit AlexaFluor 488 antibody (Molecular Probes) with Hoechst at 1:5000 in PBS/Tween ${ }^{\mathrm{TM}} / 3 \%$ (w/v) Bovine Serum Albumin for $1 \mathrm{hr}$ at room temperature. The plates were then washed three times in $250 \mu \mathrm{l}$ of PBS/0.05\% (v/v) Tween ${ }^{\mathrm{TM}} 20$ with Proclin (PBST with a Biocide preservative). $20 \mu \mathrm{l}$ of PBS was added to each well and the plates covered with a black plate seal and stored at $4{ }^{\circ} \mathrm{C}$ before being read. Plates were read using a Cellomics Arrayscan reading the $594 \mathrm{~nm}$ ( $24 \mathrm{hr}$ time point) or $488 \mathrm{~nm}$ ( $5 \mathrm{hr}$ timepoint) fluorescence to measure the ER $\alpha$ receptor level in each well. The mean total intensity was normalized for cell number giving the total intensity per cell. The data was exported into a suitable software package (such as Origin) to perform curve fitting analysis. Down-regulation of the ER $\alpha$ receptor was expressed as an $\mathrm{IC}_{50}$ value and was determined by calculation of the concentration of compound that was required to give a $50 \%$ reduction of the average maximum Total Intensity signal. $\mathrm{S}_{\text {inf }}$ is reported as a \%reduction relative to fulvestrant as a standard.

Results are tabulated below for both assays together with number of test results $(n)$ and standard error of the mean (SEM)

ER binding and ER degradation assay: Values \& Errors

\begin{tabular}{|c|c|c|c|c|c|c|c|c|}
\hline Cpd No & $\begin{array}{c}\mathrm{ER} \\
\text { bind } \\
\mathrm{pIC}_{50}\end{array}$ & $\begin{array}{c}\mathrm{pIC}_{50} \\
\mathrm{SD}\end{array}$ & $\begin{array}{c}\mathrm{pIC}_{50} \\
\mathrm{SEM}\end{array}$ & $\mathrm{n}$ & $\begin{array}{c}\mathrm{ER} \\
\mathrm{DR} \\
\mathrm{pIC}_{50}\end{array}$ & $\begin{array}{c}\mathrm{pIC}_{50} \\
\mathrm{SD}\end{array}$ & $\begin{array}{c}\mathrm{pIC}_{50} \\
\mathrm{SEM}\end{array}$ & $\mathrm{n}$ \\
\hline $\mathbf{1}$ & 9.1 & 0.98 & 0.56 & 3 & 9.5 & 0.29 & 0.03 & 130 \\
\hline $\mathbf{6}$ & 9.4 & 0.04 & 0.02 & 2 & 8.9 & 0.38 & 0.13 & 8 \\
\hline $\mathbf{7}$ & 9.2 & 0.14 & 0.08 & 3 & 8.8 & 0.15 & 0.07 & 4 \\
\hline $\mathbf{8}$ & 9.1 & 0.26 & 0.18 & 2 & 7.8 & 0.24 & 0.12 & 4 \\
\hline $\mathbf{1 5}$ & 9.0 & 0.11 & 0.05 & 5 & 10.1 & 0.11 & 0.03 & 16 \\
\hline $\mathbf{1 6}$ & 9.0 & 0.12 & 0.09 & 2 & 9.6 & 0.16 & 0.08 & 4 \\
\hline $\mathbf{1 7}$ & 8.7 & 0.27 & 0.19 & 2 & 8.7 & 0.06 & 0.04 & 2 \\
\hline
\end{tabular}

\section{PAINS screening}

Compounds were screened for known PAINS substructures, using SMARTS definitions curated by OpenEye Scientific and adapted from the SLN patterns from Baell and Holloway. ${ }^{1}$ All compounds were found to be clean against all filters. 
1. Baell, J. B.; Holloway, G. A. New Substructure Filters for Removal of Pan Assay Interference Compounds (PAINS) from Screening Libraries and for Their Exclusion in Bioassays $J$. Med. Chem., 2010, 53(7), 2719-2740. 
Molecular Formula Strings

\begin{tabular}{r|l|l|}
\hline $\mathbf{1}$ & $\mathrm{C}[\mathrm{C} @ @ \mathrm{H}] 1 \mathrm{Cc} 2 \mathrm{c} 3 \mathrm{ccccc} 3[\mathrm{nH}] \mathrm{c} 2[\mathrm{C} @ \mathrm{H}](\mathrm{N} 1 \mathrm{CC}(\mathrm{C})(\mathrm{C}) \mathrm{F}) \mathrm{c} 4 \mathrm{c}(\mathrm{cc}(\mathrm{cc} 4 \mathrm{~F}) / \mathrm{C}=\mathrm{C} / \mathrm{C}(=\mathrm{O}) \mathrm{O}) \mathrm{F}$ \\
\hline $\mathbf{6}$ & $\mathrm{C}[\mathrm{C} @ @ \mathrm{H}] 1 \mathrm{Cc} 2 \mathrm{c} 3 \mathrm{ccccc} 3[\mathrm{nH}] \mathrm{c} 2[\mathrm{C} @ @](\mathrm{N} 1 \mathrm{CC}(\mathrm{C})(\mathrm{C}) \mathrm{F})(\mathrm{C}) \mathrm{c} 4 \mathrm{c}(\mathrm{cc}(\mathrm{cc} 4 \mathrm{~F}) / \mathrm{C}=\mathrm{C} / \mathrm{C}(=\mathrm{O}) \mathrm{O}) \mathrm{F}$ \\
\hline $\mathbf{7}$ & $\mathrm{CC}(\mathrm{C})(\mathrm{CN} 1[\mathrm{C} @ \mathrm{H}] 2 \mathrm{Cc} 3 \mathrm{c} 4 \mathrm{ccccc} 4[\mathrm{nH}] \mathrm{c} 3[\mathrm{C} @ @] 1(\mathrm{CC}=\mathrm{C} 2) \mathrm{c} 5 \mathrm{c}(\mathrm{cc}(\mathrm{cc} 5 \mathrm{~F}) / \mathrm{C}=\mathrm{C} / \mathrm{C}(=\mathrm{O}) \mathrm{O}) \mathrm{F}) \mathrm{F}$ \\
\hline $\mathbf{8}$ & $\mathrm{CC}(\mathrm{C})(\mathrm{CN} 1[\mathrm{C} @ @ \mathrm{H}] 2 \mathrm{CCC}[\mathrm{C} @] 1(\mathrm{c} 3 \mathrm{c}(\mathrm{c} 4 \mathrm{ccccc} 4[\mathrm{nH}] 3) \mathrm{C} 2) \mathrm{c} 5 \mathrm{c}(\mathrm{cc}(\mathrm{cc} 5 \mathrm{~F}) / \mathrm{C}=\mathrm{C} / \mathrm{C}(=\mathrm{O}) \mathrm{O}) \mathrm{F}) \mathrm{F}$ \\
\hline $\mathbf{1 5}$ & $\mathrm{C}[\mathrm{C} @ @ \mathrm{H}] 1 \mathrm{Cc} 2 \mathrm{c} 3 \mathrm{ccccc} 3[\mathrm{nH}] \mathrm{c} 2[\mathrm{C} @ \mathrm{H}](\mathrm{N} 1 \mathrm{CC}(\mathrm{C})(\mathrm{C}) \mathrm{F}) \mathrm{c} 4 \mathrm{c}(\mathrm{cc}(\mathrm{cc} 4 \mathrm{~F}) \mathrm{OCCN} 5 \mathrm{CC}(\mathrm{C} 5) \mathrm{CF}) \mathrm{F}$ \\
\hline $\mathbf{1 6}$ & $\mathrm{C}[\mathrm{C} @ @ \mathrm{H}] 1 \mathrm{Cc} 2 \mathrm{c} 3 \mathrm{ccccc} 3[\mathrm{nH}] \mathrm{c} 2[\mathrm{C} @ @](\mathrm{N} 1 \mathrm{CC}(\mathrm{C})(\mathrm{C}) \mathrm{F})(\mathrm{C}) \mathrm{c} 4 \mathrm{c}(\mathrm{cc}(\mathrm{cc} 4 \mathrm{~F}) \mathrm{OCCN} 5 \mathrm{CC}(\mathrm{C} 5) \mathrm{CF}) \mathrm{F}$ \\
\hline $\mathbf{1 7}$ & $\mathrm{CC}(\mathrm{C})(\mathrm{CN} 1[\mathrm{C} @ @ \mathrm{H}] 2 \mathrm{CCC}[\mathrm{C} @] 1(\mathrm{c} 3 \mathrm{c}(\mathrm{c} 4 \mathrm{ccccc} 4[\mathrm{nH}] 3) \mathrm{C} 2) \mathrm{c} 5 \mathrm{c}(\mathrm{cc}(\mathrm{cc} 5 \mathrm{~F}) \mathrm{OCCN} 6 \mathrm{CC}(\mathrm{C} 6) \mathrm{CF}) \mathrm{F}) \mathrm{F}$ \\
\hline
\end{tabular}

